\title{
Chronic pneumonia despite adaptive immune response to Mycobacterium bovis BCG in MyD88-deficient mice
}

\author{
Delphine M Nicolle ${ }^{1}$, Xavier Pichon ${ }^{1}$, André Bouchot ${ }^{1}$, Isabelle Maillet ${ }^{1}$, François Erard ${ }^{1}$, \\ Shizuo Akira ${ }^{2}$, Bernhard Ryffel ${ }^{1}$ and Valérie FJ Quesniaux ${ }^{1}$ \\ ${ }^{1}$ Molecular Immunology and Embryology (IEM), CNRS, Orléans, France and ${ }^{2}$ Department of Host Defense, \\ Research Institute for Microbial Disease, Osaka University, Japan
}

\begin{abstract}
To assess the role of Toll-like receptor (TLR) signalling in host response to mycobacterial infection, mice deficient in the TLR adaptor molecule myeloid differentiation factor 88 (MyD88) were infected with the vaccine strain Mycobacterium bovis (BCG), and the immune response and bacterial burden were investigated. Macrophages and dendritic cells from MyD88-deficient mice stimulated in vitro with BCG mycobacterial antigens produced very low levels of proinflammatory cytokines, while the expression of costimulatory molecules such as CD40 and CD86 was preserved. Upon systemic infection with BCG $\left(2 \times 10^{6}\right.$ CFU i.v. $)$ MyD88deficient mice developed confluent chronic pneumonia with two log higher CFU than wild-type mice. Interestingly, the infection was controlled in liver and spleen and there was efficient systemic T-cell priming with high IFN $\gamma$ production by CD4 + splenic T cells in MyD88-deficient mice. Lung infiltrating cells showed IFN $\gamma$ production by pulmonary CD4 $+\mathrm{T}$ cells upon specific restimulation, and a reduced capacity to produce nitric oxide and IL-10. In summary, despite the dramatic reduction of the innate immune response, MyD88-deficient mice were able to mount an efficient T-cell response to mycobacterial antigens, which was however insufficient to control infection in the lung, resulting in chronic pneumonia in MyD88-deficient mice.
\end{abstract}

Laboratory Investigation (2004) 84, 1305-1321, advance online publication, 19 July 2004; doi:10.1038/labinvest.3700149

Keywords: mycobacterial infection; M. bovis BCG; innate immunity; adaptive immunity; MyD88 knockout mice; TLR (Toll-like receptors)

Toll-like receptors (TLR) are implicated in innate immunity by recognizing pathogen-associated molecular patterns (PAMPS) and activating signalling cascades in phagocytes (reviewed in Takeda et $a l^{1}$ ). From the 10 known mammalian TLR, TLR2 has been shown to heterodimerise with TLR1 or TLR6 and to recognise Gram-positive bacterial components, including peptidoglycan and lipoproteins, whereas TLR4 as a homodimer responds to Gram-negative bacterial LPS. Both TLR2 and TLR4 have been implicated in the recognition of mycobacteria such as attenuated Mycobacterium bovis BCG (BCG) or Mycobacterium tuberculosis; ${ }^{2,3}$ reviewed in Heldwein and Fenton, ${ }^{4}$ leading to dendritic cell (DC) maturation, ${ }^{5}$ reduced MHC class II expression and antigen processing ${ }^{6}$ and direct intracellular killing

Correspondence: Dr B Ryffel, MD and Dr VFJ Quesniaux, PhD, Molecular Immunology and Embryology (IEM, FRE2815) CNRS, 3B rue de la Férollerie, F-45071 Orléans Cedex 2, France.

E-mail: bryffel@cnrs-orleans.fr, quesniaux@cnrs-orleans.fr

Received 13 February 2004; revised 10 May 2004; accepted 11 May 2004; published online 19 July 2004 by macrophages. ${ }^{7}$ The TLR2 and TLR4 pathways seem prominent in mycobacterial phagocyte activation as inactivation of both TLR2 and TLR4 abrogated most activation of murine macrophages infected with live $M$. bovis BCG ${ }^{8}$ or of human DC by BCG cell wall skeleton. ${ }^{5}$ In vivo, absence of TLR2, and to a lesser extent, of TLR4, was associated with a defect of the long-term control of virulent M. tuberculosis infection. ${ }^{9-12}$

TLRs trigger a signalling pathway via Toll/IL-1 receptor (TIR) domain-containing adapters such as myeloid differentiation factor 88 (MyD88) and TIRAP. This family is growing as new TIR-containing adapters such as TRIF, more specifically involved in TLR3 and TLR4 IFN $\beta$ and IFN-inducible genes pathways, ${ }^{13,14}$ TRAM and SARM have been recently unravelled. ${ }^{15}$ MyD88 has been identified as a central adapter protein for signal transduction of TLRs and the IL-1R family. ${ }^{16}$ Specific TLR ligands induce recruitment of MyD88 to the cytoplasmic domain of TLR, resulting in NF- $\kappa \mathrm{B}$ translocation that causes transcription of IL-12, TNF and other inflammatory cytokines. ${ }^{1}$ Macrophages from MyD88 
knockout mice do not produce TNF in response to a large number of bacterial cell wall components, emphasising the central role of MyD88 for integrating signals from multiple TLR. ${ }^{17}$ However, exposure of MyD88-deficient dendritic cells (DCs) or macrophages with LPS results in expression of costimulatory molecules and delayed activation of NF- $\kappa \mathrm{B}$ and mitogen-activated protein kinases, suggesting the existence of MyD88-independent signalling pathways, ${ }^{18,19}$ which may involve TRIF and/or other TIR-containing adapters. ${ }^{13}$

In vivo, MyD88-deficient mice showed an impaired response to microbial ligands such as endotoxin, ${ }^{20}$ to IL-1 and IL-18, ${ }^{21}$ and MyD88 has been shown to be central in the systemic immune pathology of polymicrobial sepsis. ${ }^{22}$ MyD88 seems also involved in the in vivo resistance to pathogens such as Staphylococcus aureus, ${ }^{23}$ Toxoplasma gondii, ${ }^{24}$ Listeria monocytogenes ${ }^{25}$ and M. avium infection. ${ }^{26}$

In the present study, we investigated the involvement of MyD88 signalling responses to the attenuated $M$. bovis BCG vaccine strain to follow the onset of innate and adaptive immune responses rather than to the virulent $M$. tuberculosis infection, which is lethal within 4 weeks (unpublished data). Macrophages and DCs from MyD88-deficient mice were activated after $M$. bovis BCG infection in vitro in terms of costimulatory molecules expression, although the production of inflammatory cytokines was strongly reduced. In vivo, MyD88-deficient mice did control systemic M. bovis BCG infection, and were able to mount a T-cell response with high IFN $\gamma$ production to mycobacterial antigens upon ex vivo restimulation. However, in the lung, absence of MyD88 resulted in chronic pneumonia and increased mycobacterial burden.

\section{Materials and methods}

\section{Mice and Infection}

MyD88-deficient mice, 6-12 weeks old (obtained from S Akira; Kawai et $a l^{20}$ ) and their wild-type control littermates were backcrossed and bred under specific-pathogen-free conditions in the Transgenose Institute animal breeding facility (Orleans, France). Alternatively, C57Bl/6 mice were also used as wild-type controls in some in vitro experiments with similar results. Mice were injected intravenously with a dose of $2 \times 10^{6} \mathrm{CFU} M$. bovis BCG (Pasteur strain \#1173P2, Pasteur Institute, Paris). All animal experiments complied with the French Government's ethical and animal experiment regulations. Groups of mice were infected and three to four mice were killed per time point. The infected mice were monitored regularly for clinical status and weighed weekly.

\section{Quantification of Viable Mycobacteria in Organs}

At specific time points, mice were killed and their lung, liver and spleen aseptically removed and weighed. One-half of each organ was homogenised in $0.9 \% \mathrm{NaCl}$ solution containing $0.04 \%$ Tween-20 (Sigma). Serial dilutions of the homogenates were plated in duplicate onto 7H11 Middlebrook agar supplemented with 10\% OADC (Difco Laboratories, Detroit, MI, USA) and $0.5 \%$ glycerol. Plates were incubated at $37^{\circ} \mathrm{C}$ and CFU enumerated after 21 days. Data are presented as $\log _{10}$ of the number of CFU per organ. The number of CFU per mg of organ, calculated to take into account variations in organ weight, gave essentially the same outcome and are not presented.

\section{Histopathology}

Samples of lung, liver and spleen were fixed in 10\% buffered formalin (Shandon, Pittsburgh, PA, USA) before paraffin embedding. Sections $(3 \mu \mathrm{m})$ were stained with haematoxylin and eosin, or ZiehlNeelsen acid-fast stain for evaluation of pathologic changes and bacillary load, respectively. Granulomas were quantified by counting 10 microscopic fields at $\times 200$ magnification. Typical clusters of more than 10 mononuclear cells were counted as a granuloma.

\section{Immunohistochemistry}

Samples of lung, liver and spleen were embedded in Tissue-Tek (Sakura, Zoeterwoude, The Netherlands) in cryomoulds, immediately frozen on dry ice, and stored at $-80^{\circ} \mathrm{C}$. The frozen tissues were cut at $6 \mu \mathrm{m}$ thickness on a cryostat (Leica, Nussloch, Germany), air-dried and stored at $-80^{\circ} \mathrm{C}$. Fixation in acetone $\left(10 \mathrm{~min}\right.$ at $\left.4^{\circ} \mathrm{C}\right)$ or paraformaldehyde $4 \%$ was performed just before immunolabelling. After a rinse in PBS, the sections were saturated with normal rabbit serum before incubation for $16 \mathrm{~h}$ at $4^{\circ} \mathrm{C}$ with the primary antibody. Rabbit antiserum to inducible nitric oxide synthase (iNOS) was from Professor J Pfeilschifter, University of Frankfurt, Germany. The sections were then washed in PBS and incubated for $30 \mathrm{~min}$ at room temperature with the appropriate biotinylated secondary antibody. Avidin-biotin complexes was added to the sections for $30 \mathrm{~min}$ (ABC vector kit, Vector, Burlingame, CA, USA), washed and revealed with DAB substrate (Dako, Glostrup, Denmark). After rinsing in PBS, the sections were mounted in Eukitt (Kindler \& Co., Freiburg, Germany).

\section{Primary Macrophage and DCs Cultures}

Murine bone marrow cells were isolated from femurs and differentiated into macrophages after culturing at $10^{6} \mathrm{cells} / \mathrm{ml}$ for 7 days in Dulbecco's 
minimal essential medium (DMEM, Sigma) supplemented with $20 \%$ horse serum and $30 \%$ L929 cellconditioned medium as a source of M-CSF (as described in Muller et $a l^{27}$ ). Three days after washing and reculturing in fresh medium, the cell preparation contained a homogenous population of macrophages. Alternatively, murine bone marrow cells were differentiated into myeloid DCs after culturing at $2 \times 10^{5}$ cells $/ \mathrm{ml}$ for 10 days in RPMI supplemented with $10 \%$ foetal calf serum and $4 \%$ J558L cell-conditioned medium as a source of GM-CSF with transfer in fresh medium on days 3, 6 and $8 .^{28}$

\section{Stimulation of Macrophages and DCs}

The bone marrow-derived macrophages and DCs were plated in 96-well microculture plates (at $10^{5}$ cells/well) and stimulated with LPS (Escherichia coli, serotype O111:B4, Sigma, St Louis, MO, USA, at $100 \mathrm{ng} / \mathrm{ml}$ ), or infected $M$. bovis BCG (Pasteur strain \#1173P2, Pasteur Institute, Paris; at a multiplicity of infection (m.o.i.) of 2 bacteria/cell). The BCG preparations used for stimulation were a lyophilised preparation of BCG culture supernatant $(10 \mu \mathrm{g} / \mathrm{ml})$, heat-killed $M$. bovis BCG $(10 \mu \mathrm{g} / \mathrm{ml})$, or extended freeze-dried $\mathrm{BCG}^{29}(10 \mu \mathrm{g} /$ $\mathrm{ml}$ ), all kind gifts of Professor G Marchal (Pasteur Institute, Paris, France), BCG lipomannan (LM), lipoarabinomannan (LAM) and PIMs were kind gifts from Drs J Nigou, G Puzo and M Gilleron (IPBS, CNRS, Toulouse, France) and were used at $10 \mu \mathrm{g} / \mathrm{ml}$. Cell supernatants were harvested after $18-24 \mathrm{~h}$ of stimulation in the presence of $\operatorname{IFN} \gamma(100 \mathrm{U} / \mathrm{ml})$ for TNF, IL-12 p40, IL-10, IL-6 and nitrite measurements, and analysed immediately or stored at $-20^{\circ} \mathrm{C}$.

\section{Cytokine ELISA}

Commercially available ELISA reagents for TNF, IL-12p40, IL-10, IL-6 and IFN $\gamma$ were used as recommended (Duoset R\&D Systems, Abingdon, UK).

\section{Nitrite Measurements}

Nitrite concentrations in cell supernatants were determined using the Griess reagent in presence of $1 \% p$-aminobenzene-sulphonamide and $0.1 \% n$-1napthylethylene-diamide in $2.5 \%$ phosphoric acid as described. ${ }^{30}$ The absorbance at $540 \mathrm{~nm}$ was measured after $30 \mathrm{~min}$ of incubation.

\section{Flow Cytometry Analysis}

Stimulated macrophages and DCs cultured on nontissue culture-treated Petri dishes were harvested with cold PBS and gentle pipetting. Cells were stained for cell surface markers using fluorescent labelled Abs to CD11b-PercP-Cy5.5 (clone H1/70), CD11c-APC (clone HL3), CD40-PE (clone 3/23), CD86-FITC (clone GL1), IA/IE (clone 2G9) (BD PharMingen San Diego, CA, USA). All staining procedures were performed on $0.2 \mu \mathrm{g} / 10^{6}$ cells in $50 \mu \mathrm{l} \mathrm{PBS}$ containing $0.5 \%$ BSA for $20 \mathrm{~min}$ at $4^{\circ} \mathrm{C}$. Flow cytometry was performed on an LSR analyser using CellQuest software (BD Immunocytometry Systems, San Jose, CA, USA).

Alternatively, FACS analysis was performed on inflammatory cells from bronchoalveolar lavage or infected lungs described. ${ }^{31,32}$ In brief, mice were deeply anaesthetised with xylazine-ketamine, bronchoalveolar lavage with $\mathrm{NaCl} 0.9 \%$ was performed and the mice were perfused with $0.02 \%$ EDTA-PBS until the tissue turned white. After removal, lung tissue was sliced into $1-2 \mathrm{~mm}^{3}$ pieces and was incubated in RPMI 1640 (Gibco, Paisley, Scotland, UK) containing 5\% foetal calf serum, antibiotics (Penicillin $100 \mathrm{U} / \mathrm{ml}$-streptomycin $100 \mu \mathrm{g} / \mathrm{ml}$ ), $10 \mathrm{mM}$ HEPES (Gibco) and collagenase $(150 \mathrm{U} / \mathrm{ml})$, DNase $(50 \mathrm{U} / \mathrm{ml}$; Sigma, St Louis, $\mathrm{MO}$, USA). After $1.5 \mathrm{~h}$ of incubation at $37^{\circ} \mathrm{C}$, single-cell suspension was obtained by vigorous pipetting. Cells were washed three times in PBS containing $0.01 \% \mathrm{NaN}_{3}$ and $0.5 \% \mathrm{BSA}$, and stained as above using fluorescent labelled Abs to CD4PerCP (clone RM4-5), CD8-APC (clone 53-6.7), CD44-PE (clone IM7), CD25-FITC (clone 7D4), CD11b-PE (clone M1/70), CD11c-APC (clone HL3) and Ly-6G-PE (clone RB6-8C5) (all from BD Pharmingen).

\section{Confocal Microscopy}

Macrophage monolayers were established by plating $10^{5}$ cells in $0.2 \mathrm{ml}$. DMEM supplemented with $10 \%$ FCS onto sterile glass coverslips. After overnight attachment at $37^{\circ} \mathrm{C}$ in humidified air containing $5 \%$ $\mathrm{CO}_{2}$, coverslips were transferred into 24-well microtitre plates containing DMEM for $4 \mathrm{~h}$.

BCG internalisation was studied using fluorescent $M$. bovis BCG expressing GFP (kind gift from V Snewin, London, UK). BCG-GFP stored at $-80^{\circ} \mathrm{C}$ was rapidly thawed, passed 30 -fold through a $25 \mathrm{G}$ needle, then 10 -fold through a $30 \mathrm{G}$ needle, sonicated six times for $15 \mathrm{~s}$, and immediately added to the cultures at a m.o.i. of 1 . After $2 \mathrm{~h}$ at $37^{\circ} \mathrm{C}$ under a humidified atmosphere containing $5 \% \mathrm{CO}_{2}$, the medium was removed, the cultures washed once with warm phosphate-buffered saline (PBS, pH 7.2) and fixed with paraformaldehyde $4 \%$ in PBS. After overnight fixation, macrophages on coverslips were washed once in PBS for $10 \mathrm{~min}$. Cells were then permeabilised for 3 min with $0.1 \%$ Triton X-100 in PBS, washed twice 5 min with PBS, quenched with $50 \mathrm{mM} \mathrm{NH}_{4} \mathrm{Cl}$ in PBS for $30 \mathrm{~min}$, preincubated for 30 min with $1 \%$ BSA in PBS. To stain F-actin, macrophages were incubated for $20 \mathrm{~min}$ with $\beta$-phalloidin conjugated to rhodamine at $5 \mathrm{U} / \mathrm{ml}$ 
(Molecular Probes, Eugene, OR, USA) followed by two 5-min wash in PBS. Coverslips were mounted using DAKO mounting medium. BCG-GFP internalisation was assessed using a fluorescence Leica DM IRBE microscope (Leica, Reuil Malmaison, France; $\times 40$ oil immersion objective) by counting the macrophages containing one or two isolated intracellular bacteria and the non infected macrophages over 10 different observation fields per slide (three slides per experiment and four experiments in total). The slides were counted blindly. The percentage of infected macrophages was determined as infection index.

$\mathrm{NF} \kappa \mathrm{B}$ translocation was studied 2, 4 and $18 \mathrm{~h}$ after infection of macrophage monolayers with BCG (at a m.o.i. of 2) by staining with goat antibodies to $\mathrm{NF} \kappa \mathrm{B}$ (Santa Cruz, CA, USA), and revealed with biotinylated secondary antibodies and streptavidin-Alexa (both from Molecular Probes, OR, USA). Overlays of 10 images spanning $1.6 \mu \mathrm{m}$ were used to assess $\mathrm{NF} \kappa \mathrm{B}$ cytosolic and nuclear staining.

\section{Splenocyte Restimulation}

Spleens were aseptically removed from uninfected or infected control and MyD88-deficient mice and splenocyte suspensions were prepared by gentle teasing and repeated pipeting in DMEM supplemented with $10 \%$ foetal calf serum. After washing, splenocytes were seeded in 96-well microtitre plates (at $5 \times 10^{5}$ cells/well) in the same medium, in the presence of soluble BCG antigens (Sup BCG, $30 \mu \mathrm{g}$ / $\mathrm{ml}$ ), live BCG (at a m.o.i. of 2) or heat-killed Listeria monocytogenes (HKLM) (100 bacteria/cell). Alternatively, lung infiltrating cells (at $5 \times 10^{5}$ cells/well) or CD4 + cells purified from spleen and lung (at $10^{5}$ cells/well), isolated by positive selection magnetic cell sorting with MACS CD4 Microbeads (clone GK1.5, Milteny Biotec, Auburn, CA, USA), were stimulated as above. IFN $\gamma$ production in the supernatants after $48 \mathrm{~h}$ of incubation was quantified by ELISA.

Cells restimulated as above were also analysed for intracellular IFN $\gamma$ staining of CD4 + or CD8 $+\mathrm{T}$ cells. After $12 \mathrm{~h}$ of restimulation, addition of GolgiStop to block protein transport and incubation for further $6 \mathrm{~h}$, cells were labelled with anti CD4PerCP (clone RM4-5) or CD8-APC (clone 53-6.7) antibodies, fixed and permeabilised, and intracellular IFN $\gamma$ was stained with antibodies to IFN $\gamma$ FITC (clone XMG1.2; according to BD Cytofix/ Cytoperm kit manual; all reagents from BD Biosciences).

\section{Statistical Analysis}

The significance $(P)$ was assessed using Student's $t$-tests, unless otherwise stated (level of significance of $P<0.05$ ).

\section{Results}

Impaired TNF, IL-12p40, IL-6 and Nitric Oxide Production in BCG-Activated MyD88-Deficient Macrophages

Mycobacteria and mycobacterial antigens were reported to activate macrophages and DCs through TLR2 and TLR4. ${ }^{2,5}$ We first verified how macrophages deficient for MyD88 responded to live BCG or BCG antigens. Wild-type macrophages produced abundant TNF, IL-12p40, IL-6 and nitric oxide after infection with live BCG, or stimulation by heatkilled BCG (HKBCG), BCG killed by lyophilisation (BCG Lyoph), or soluble antigens released in BCG culture supernatant (Sup BCG; Figure 1a-d). The levels of cytokines and nitrite produced in response to BCG fractions were comparable to those obtained after LPS stimulation. No IL-10 was detected (data not shown). In contrast, MyD88-deficient macrophages were unable to respond to stimulation by killed BCG (HKBCG or BCG Lyoph) or by BCG soluble antigens, with no detectable TNF, IL-12p40, IL-6, IL-10 and low nitric oxide levels. However, a minimal stimulation was observed after infection of MyD88-deficient macrophages with live BCG, yielding very low ( $1 \mathrm{ng} / \mathrm{ml})$ TNF, IL-12p40, IL-6 and nitric oxide release (Figure 1a-d). Similar results were obtained after 24 and $48 \mathrm{~h}$ stimulation, thus excluding that the low cytokine levels were merely due to a delayed response. $\mathrm{NF} \kappa \mathrm{B}$ translocation, observed by confocal microscopy 2 and $4 \mathrm{~h}$ after BCG infection in control macrophages was undetectable in MyD88deficient macrophages at $2-18 \mathrm{~h}$ postinfection (data not shown). Therefore, the response to BCG antigens was greatly reduced in MyD88-deficient macrophages, with live BCG inducing a minimal cytokine and nitric oxide release by an MyD88-independent pathway, whereas there was no response to particulate or soluble BCG antigens.

\section{Absence of MyD88-Deficient Macrophage Activation in Response to Purified BCG Antigens}

Mycobacterial lipids traffic within infected macrophages and are released to the extracellular space to be taken up by uninfected bystander cells. ${ }^{33}$ Several soluble, purified mycobacterial antigens have been shown to signal through TLR2, including PIM2, PIM6 and LM. ${ }^{2,34,35}$ Here, we show that LM from BCG, but not LAM, stimulates high levels of TNF, IL12 and nitric oxide in wild-type macrophages, and this response was absent in MyD88-deficient macrophages (Figure 2a-c). Wild-type macrophages stimulated with PIM2 and PIM6 release TNF and nitric oxide and low levels of IL-12p40, but these responses were abrogated in MyD88-deficient macrophages (Figure 2d-f). Based on these results, we conclude that although infection with live BCG triggered both MyD88-dependent and -independent pathways, no proinflammatory signals were 

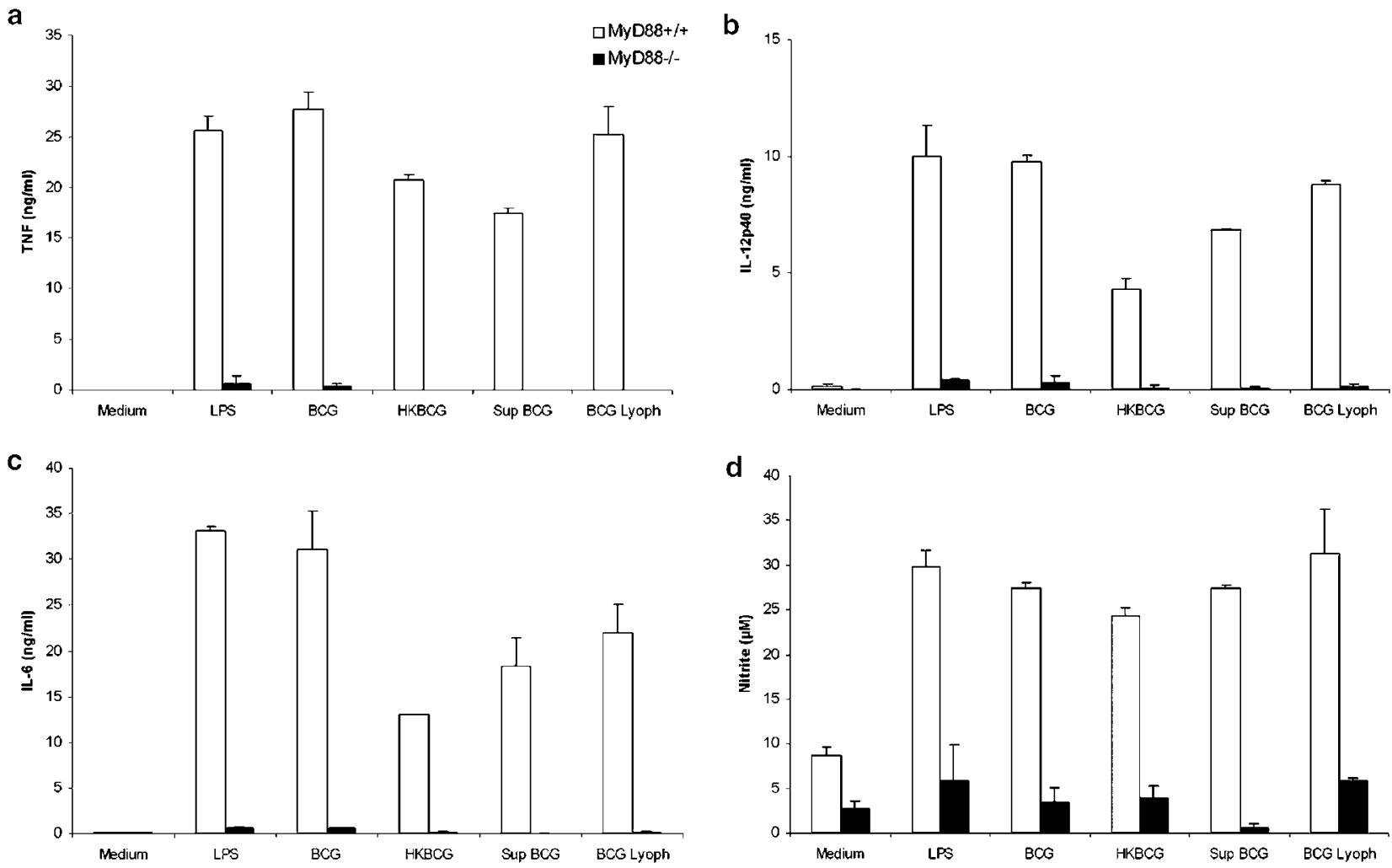

Figure 1 Impaired TNF, IL-12p40, IL-6 and nitric oxide production by BCG-activated MyD88-deficient macrophages. Bone marrowderived macrophages (BMDM) from MyD88-deficient (MyD88-/-) or control (MyD88 + / +) mice were infected with BCG (at a m.o.i. of 2) or were incubated with LPS (100 ng/ml), heat-killed BCG (HKBCG, $10 \mu \mathrm{g} / \mathrm{ml}$ ), a lyophilised preparation of BCG (BCG Lyoph, $10 \mu \mathrm{g} / \mathrm{ml})$ or a soluble fraction of BCG culture (Sup BCG, $10 \mu \mathrm{g} / \mathrm{ml}$ ) for $24 \mathrm{~h}$. TNF (a), IL-12p40 (b), IL-6 (c) and nitrite (d) were measured in the supernatants. Results are mean \pm s.d. from $n=2$ mice and are from one representative experiment out of five independent experiments.

obtained from isolated mycobacterial antigens on MyD88-deficient macrophages.

\section{Impaired Response of MyD88-Deficient DCs to BCG}

Next, we tested how DCs responded to BCG infection and to stimulation with mycobacterial antigens in the absence of functional MyD88 pathway. DC derived from MyD88-deficient bone marrow showed a strongly reduced response to live BCG infection or to BCG fractions. Essentially, no TNF, IL-12p40 or IL-6 could be detected in response to stimulation of MyD88-deficient DC with HKBCG or with soluble fraction of BCG culture supernatant (Figure 3a-c), while MyD88-deficient DC infected with live BCG, or stimulated with a preparation extended dry-frozen lyophilised BCG (EDF1) produced low levels of TNF, IL-12p40 and IL-6 (Figure 3a-c). IL-12 p70 was detected in wild-type DC stimulated with LPS, live BCG or Lyoph BCG but was undetectable in MyD88-deficient DC supernatants (data not shown). Low levels of nitric oxide were detected after incubation of MyD88-deficient DC with BCG, HKBCG and BCG Lyoph, but not with the soluble fraction of BCG culture supernatant (Figure 3d). Similar results were obtained after $48 \mathrm{~h}$ of stimulation (data not shown). Purified BCG antigens such as PIM2 or PIM6 induced low levels of TNF and IL-12 p40 secretion in wild-type DC, but not in MyD88-deficient DC (data not shown).

Therefore, live BCG induced low levels of TNF, IL-12p40, IL-6 and nitric oxide in DC in the absence of functional MyD88 pathway.

\section{MyD88-Independent CD40 and CD86 Upregulation by BCG in Macrophages and DCs}

We then asked whether the expression of costimulatory molecules by macrophages is inducible in the absence of MyD88. As shown in Figure 4, LPS and BCG induce similar CD40 and CD86 expression on MyD88-deficient and wild-type macrophages. Similar results were obtained with DCs (Figure 5). Therefore, the upregulation of the costimulatory molecules in response to BCG or LPS is MyD88independent in both antigen-presenting cell populations.

The level of MHC class II expression followed a different regulation as it slightly decreased in LPS or BCG stimulated wild-type macrophages and DCs whereas it increased in MyD88-deficient cells (Figures 4 and 5). 

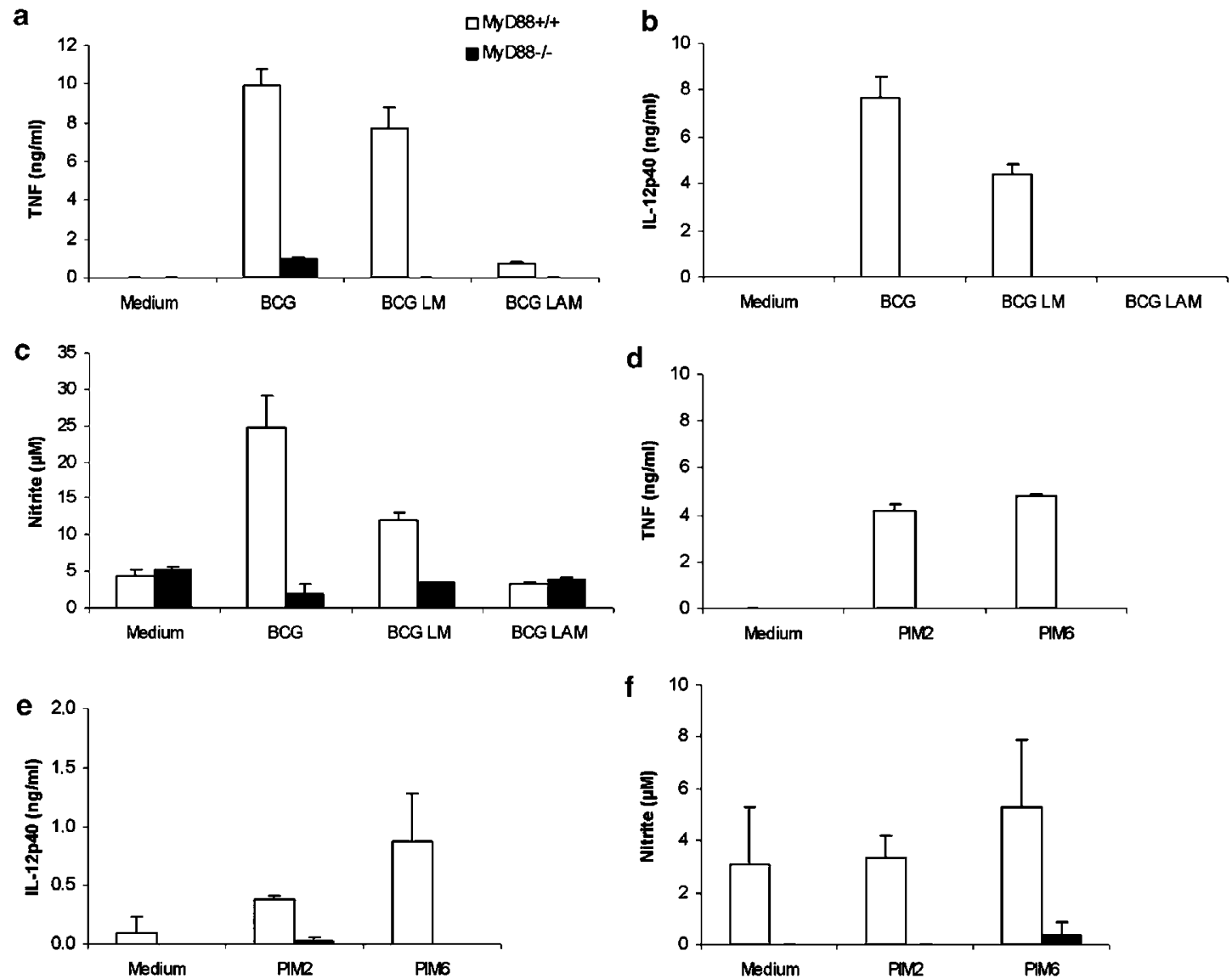

Figure 2 Absence of TNF, IL-12p40 and nitric oxide production by purified mycobacterial antigen-stimulated MyD88-deficient macrophages. BMDM from MyD88-deficient (MyD88-/-) and control (MyD88 $+/+$ ) mice were infected with BCG (at a m.o.i. of 2) or stimulated with BCG LM (10 $\mu \mathrm{g} / \mathrm{ml})$, BCG LAM (10 $\mu \mathrm{g} / \mathrm{ml}, \mathbf{a}-\mathbf{c})$, PIM2 or PIM6 (10 $\mu \mathrm{g} / \mathrm{ml}, \mathbf{d}-\mathbf{f})$ for $24 \mathrm{~h}$. TNF (a, d), IL-12p40 (b, e), and nitric oxide (c, f) were measured in the supernatants. Results are mean \pm s.d. from $n=2$ mice and are from one representative experiment out of three independent experiments.

\section{Reduced Internalisation of BCG in Macrophages of MyD88-Deficient Mice}

To investigate whether MyD88 signalling might be involved in internalisation of mycobacteria, we infected macrophages from wild-type and MyD88deficient mice with fluorescent, GFP-transfected BCG and analysed internalisation by confocal microscopy. Here, we show that internalisation is clearly reduced in MyD88-deficient macrophages (Table 1). We further compared internalisation of mycobacteria in MyD88-deficient vs TLR4- and TLR2-deficient macrophages. Absence of both TLR4 and TLR2 deficiency was associated with a significant reduction of internalisation, which was, however, less pronounced than in MyD88-deficient macrophages (data not shown). Therefore, TLRs are not only sensing pathogens, but TLRs and MyD88 seem to convey a signal for the intracellular uptake of mycobacteria.

Based on these in vitro data, we could hypothesise that the inflammatory response to BCG-secreted antigens signalling through TLR2 would be reduced in MyD88-deficient mice, although macrophages and DCs could show some activation upon contact with live BCG. To understand the net effect of the MyD88 signal deficiency on the control of BCG infection in vivo, we next infected MyD88-deficient mice with BCG.

\section{MyD88-Deficient Mice Survive BCG Infection}

MyD88-deficient and wild-type mice infected with live BCG $\left(2 \times 10^{6} \mathrm{CFU}\right.$ per mouse i.v.) showed neither clinical signs nor body weight loss during the 8-month period of the experiment. The organ weights were recorded as an indicator of inflammation. At day 28 post infection, there was an increase in relative weights of liver (Figure $6 a, P<0.01$ ) and spleen $(P>0.05$, data not shown), which were less pronounced in MyD88-deficient than in wild-type mice. This may be indicative of reduced proinflammatory cytokines production in MyD88-deficient mice, although no difference in the systemic cytokine serum levels of MyD88-deficient and wild-type mice was observed: IL-12p40 serum levels were increased on day 28 and reduced thereafter, 
a

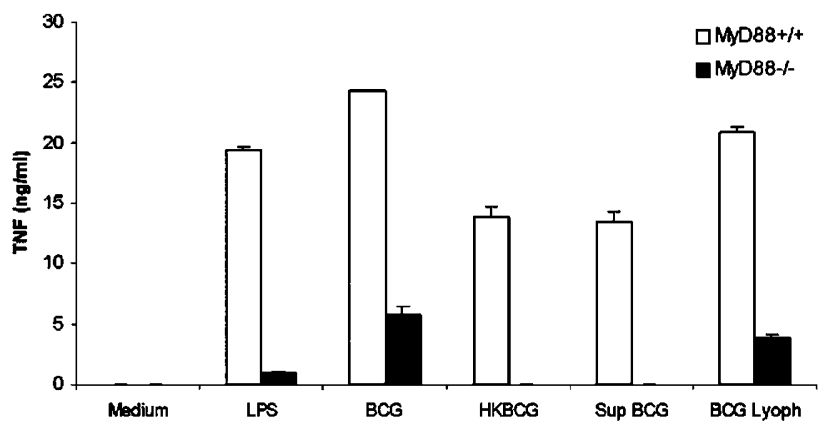

C

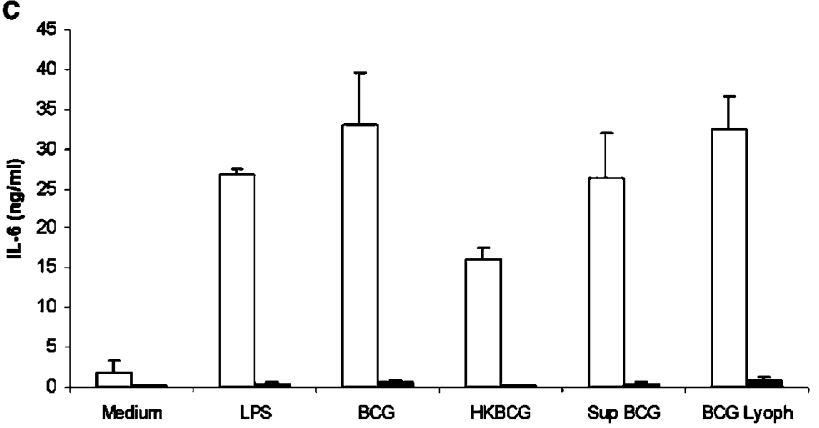

b
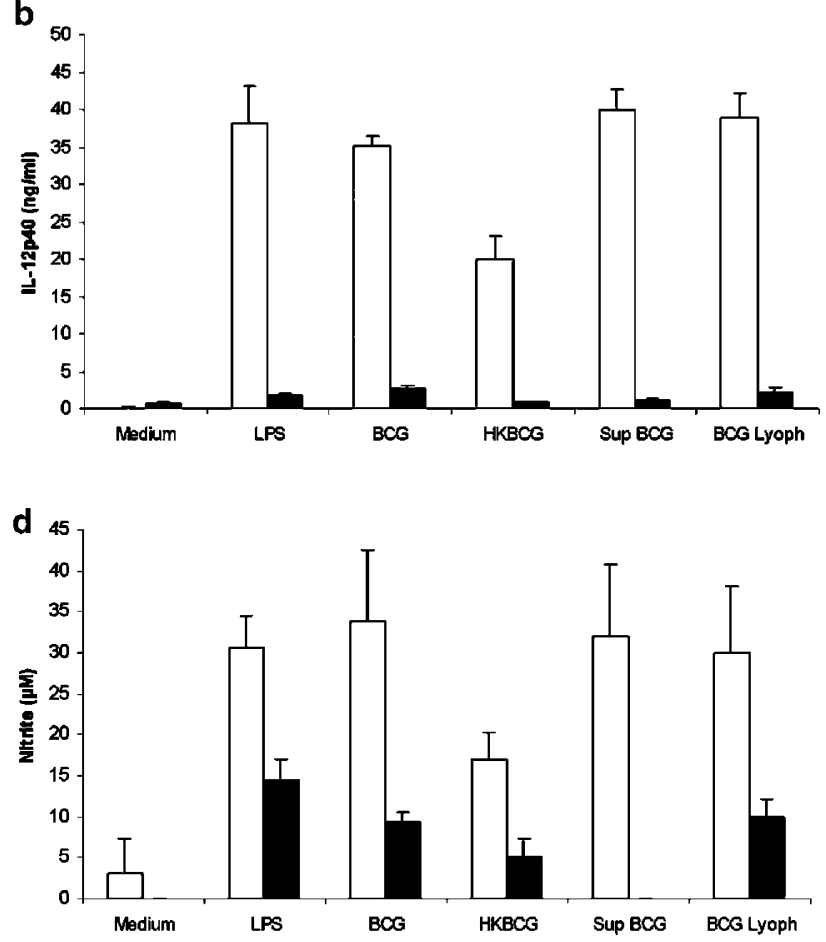

Figure 3 Reduced TNF, IL-12p40, IL-6 and nitric oxide production by BCG-activated MyD88-deficient DCs. Bone marrow-derived DCs from MyD88-deficient (MyD88-/-) and control (MyD88 + / +) mice were infected with BCG (at a m.o.i. of 2) or were incubated with LPS $(100 \mathrm{ng} / \mathrm{ml})$, heat-killed BCG (HKBCG, $10 \mu \mathrm{g} / \mathrm{ml}$ ), a lyophilised preparation of BCG (BCG Lyoph, $10 \mu \mathrm{g} / \mathrm{ml}$ ) or a soluble fraction of BCG culture (Sup BCG, $10 \mu \mathrm{g} / \mathrm{ml}$ ) for $24 \mathrm{~h}$. TNF (a), IL-12p40 (b), IL-6 (c) and nitrite (d) were measured in the supernatants. Results are mean + s.d. from $n=2$ mice and are from one representative experiment out of three independent experiments.

both in MyD88-deficient and control mice, and low TNF and IL-6 levels were measured on day 28 in both groups of mice (data not shown). The increase in liver and spleen weights resolved in both groups by day 56, indicative of a transient systemic inflammation (Figure 6a). The clearance of bacilli from liver (Figure 6b) and spleen (data not shown) during the 6 months postinfection period were similar in MyD88-deficient and control mice.

Histological studies show that the composition and size of liver granuloma are comparable in MyD88-deficient and control mice (Figure 6d and e). The number of hepatic granuloma decreased during infection-time in both groups (Figure 6c), which was coincidental with the decrease of CFU by $2 \log _{10}$ between days 28 and 112 (Figure 6b). Therefore, the data suggest that the control of systemic BCG infection is independent of MyD88 signalling.

\section{Uncontrolled, Chronic BCG Infection in the Lung of MyD88-Deficient Mice}

The lung is the main target organ for mycobacterial infection, even after an intravenous infection. Macroscopically, nodules appear on the surface of MyD88-deficient lung at 4 months postinfection and become prominent at 8 months postinfection, whereas no nodules could be seen on the wild-type lung (Figure 7a). Furthermore, MyD88-deficient mice showed a trend towards higher relative lung weights, indicative of enhanced local inflammation (Figure 7b). Significantly higher CFU counts were seen in the lung of MyD88-deficient mice already 28 days postinfection, which increased further at 4 months and reached a plateau at 8 months postinfection (Figure 7c), whereas wild-type mice controlled the BCG bacilli in the lung at 2-4 months postinfection (Figure 7c). The difference of pulmonary bacillary burden in MyD88-deficient vs wildtype mice reached almost $2 \log _{10}, 4-8$ months postinfection.

Microscopic examination of the lungs revealed a more pronounced and diffuse infiltration with mononuclear cells of the alveolar septae, starting on day 112 and most prominent on day 224 (Figure $8 \mathrm{a}-\mathrm{h}$ ), with no distinct granuloma formation in MyD88-deficient lung sections. Furthermore, bacilli were abundant within macrophages and some were visible extracellularly in the alveolar space of MyD88-deficient lung, although they were scarce in controls (Figure 8i and j). Expression of iNOS was evident in MyD88-deficient lung, in line with the increased macrophage infiltration relative to controls at day 224 (Figure 8k and l). It is established that the high oxygenisation of the alveolar space represents a growth advantage for mycobacteria explaining the preferential growth of the mycobacteria in the lung. In the presence of a normal innate immune response alveolar macrophages are able 

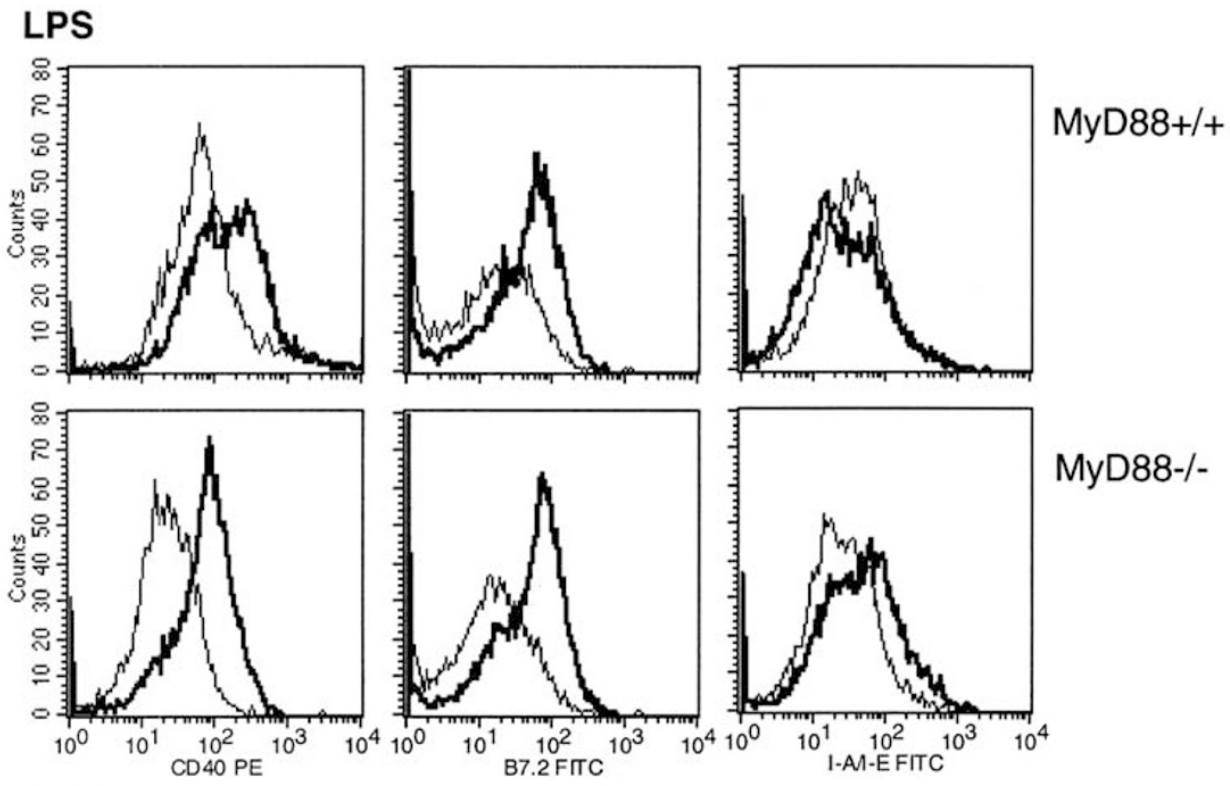

MyD88-/-

\section{BCG}
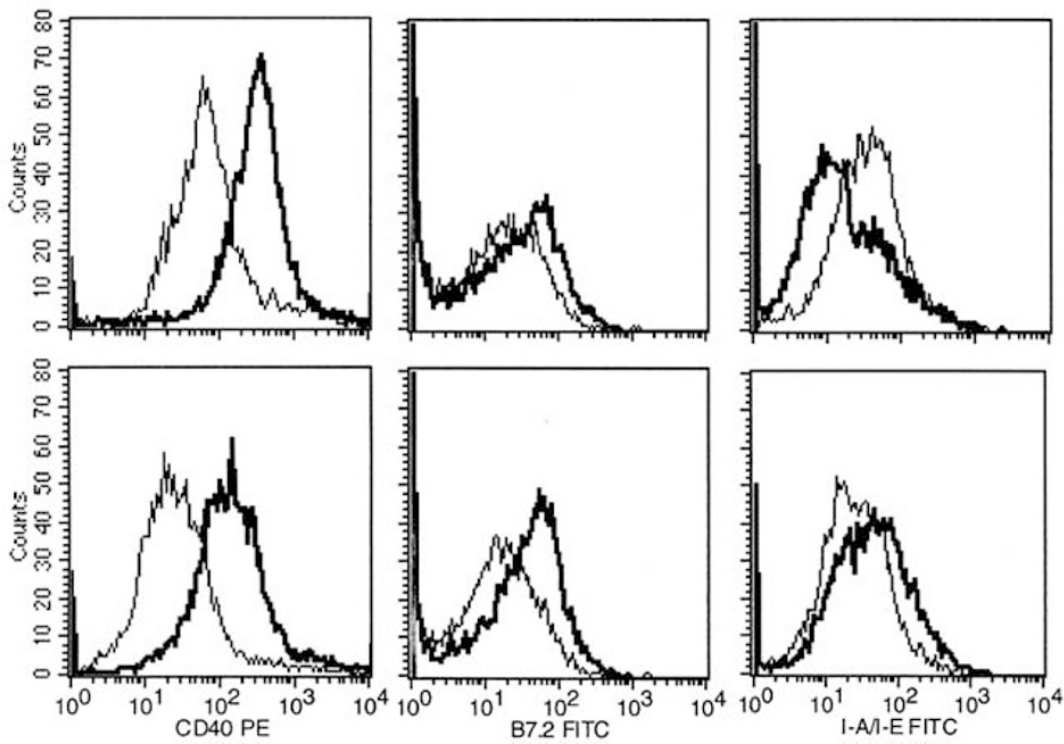

MyD88+/+

MyD88-/-

Figure 4 Unimpaired CD40 and CD86 expression on LPS and BCG-stimulated MyD88-deficient macrophages. Murine BMDM (>96\% $\mathrm{CD}_{11} \mathrm{~b}^{+}$) were either unstimulated (thin line) or stimulated by LPS ( $100 \mathrm{ng} / \mathrm{ml}$ ) or live BCG (at a m.o.i. of 2 ) for $18 \mathrm{~h}$ (thick line). CD40, CD86 (B7.2) and MHC class II (I-A/I-E) expression was analysed by flow cytometry. Results are from $n=2$ mice and are from one representative experiment out of three.

to control mycobacterial growth, while MyD88deficient macrophages with a reduced capacity to internalise mycobacteria and defective proinflammatory response are unable to control mycobacterial growth resulting a progressive, chronic pulmonary infection.

\section{T-Cell Response to BCG in the Absence of MyD88}

Although the proinflammatory response of MyD88deficient APC is severely reduced, MyD88 signalling is dispensable for the upregulation of costimulatory molecules upon mycobacteria activation of APC (Figures 4 and 5). Therefore, we asked whether Tcell activation in vivo might be compromised in the absence of MyD88. Isolated spleen cells from BCG infected mice at 4 weeks were restimulated with soluble BCG antigens ex vivo. We found an almost normal IFN $\gamma$ production by MyD88-deficient spleen cells in response to BCG antigens, whereas there was very weak response to an irrelevant antigen, HKLM (Figure 9a).

To further analyse the CD4 + T-cell response in MyD88-deficient mice, CD4 + spleen cells from day 28 infected mice were isolated and restimulated 

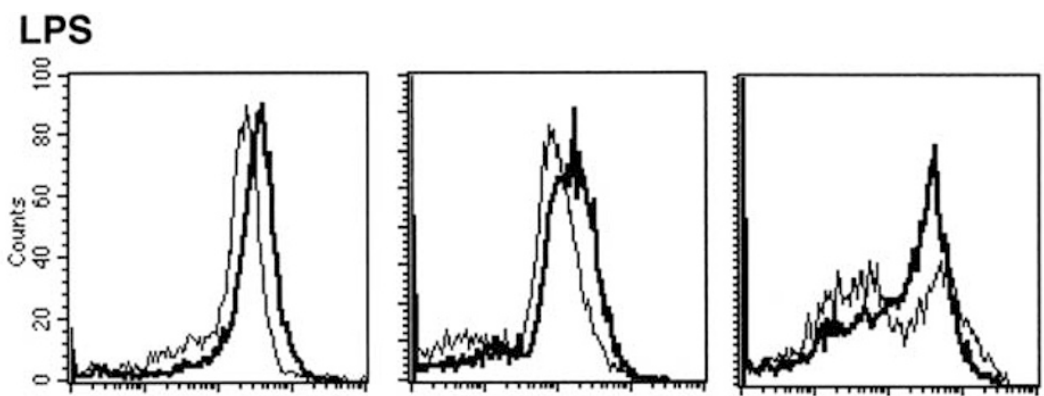

MyD88+/+
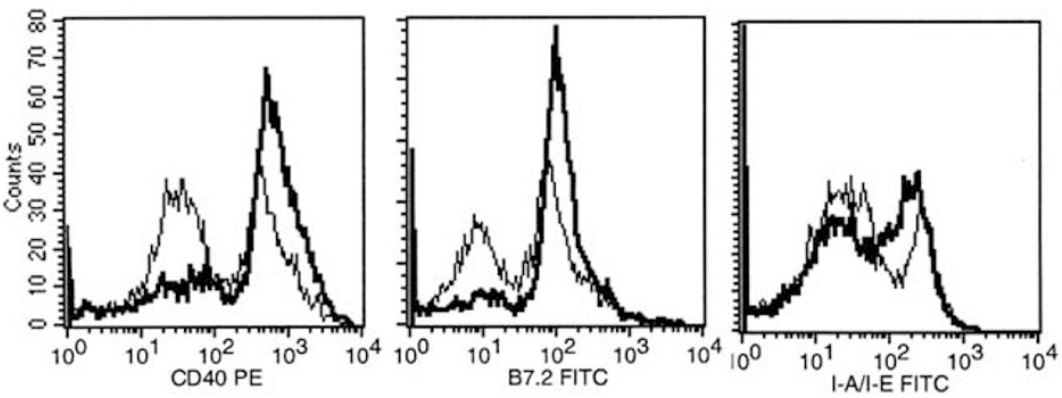

MyD88-/-
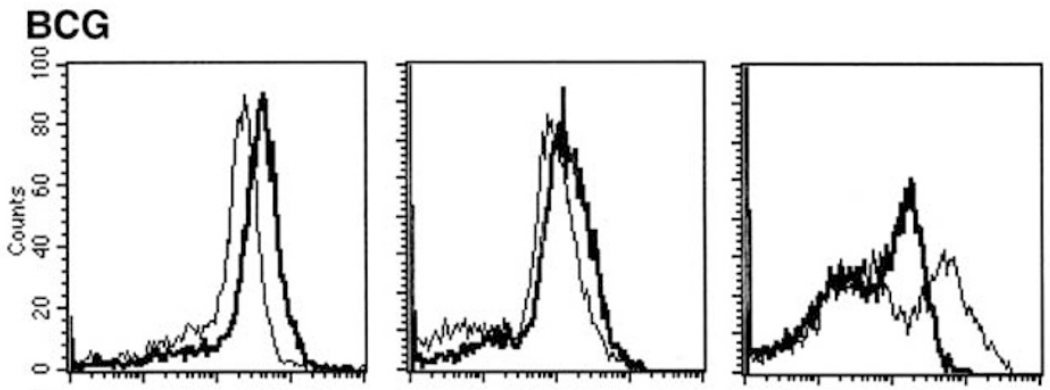

MyD88+/+
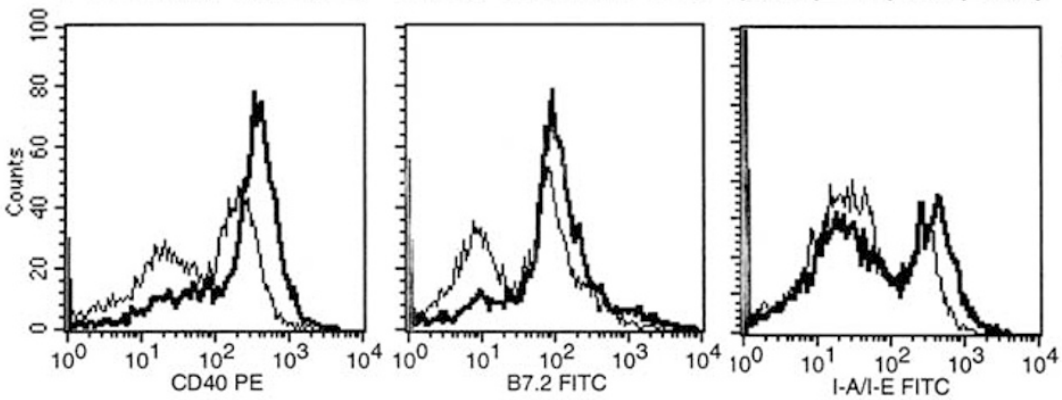

MyD88-/-

Figure 5 Unimpaired CD40 and CD86 expression on LPS and BCG-stimulated MyD88-deficient DCs. Murine bone marrow-derived DCs $\left(93-97 \%\right.$ CD $11 \mathrm{c}^{+}$) were either unstimulated (thin line) or stimulated by LPS (100 ng/ml) or live BCG (at a m.o.i. of 2 ) for $18 \mathrm{~h}$ (thick line). CD40, CD86 (B7.2) and MHC class II (I-A/I-E) expression was analysed by flow cytometry. Results are from $n=2$ mice and are from one representative experiment out of three.

Table 1 Reduced internalisation of GFP-BCG by MyD88deficient macrophages

\begin{tabular}{lccc}
\hline Mouse genotype & Infection index & Uptake (\%) & $\mathrm{P}$ \\
\hline Wild type & $4.20 \pm 1.56$ & 100 & \\
MyD88-I- & $2.23 \pm 1.15$ & 53.2 & $<0.01$ \\
\hline
\end{tabular}

Results expressed as the mean \pm s.d. of the percentage of macrophages infected with isolated GFP-BCG, $n=4$ mice per genotype, the statistical test C1 from Fisher-Yates-Terry was used.

ex vivo (Figure 9b). IFN $\gamma$ production by $\mathrm{CD} 4+\mathrm{T}$ cells from MyD88-deficient and control mice was similar upon restimulation with soluble BCG anti- gens, and was specific as no response was triggered by HKLM.

Therefore, the data indicate for the first time that MyD88 signalling is not required to mount an initial antigen-specific T-cell response to mycobacteria.

\section{Pulmonary Immune Responses to BCG in MyD88-Deficient Mice}

In view of the slow progression of chronic pulmonary mycobacterial infection, we asked whether the expression of IFN $\gamma$ as a hallmark of protective T-cell immunity is reduced during disease progression in 

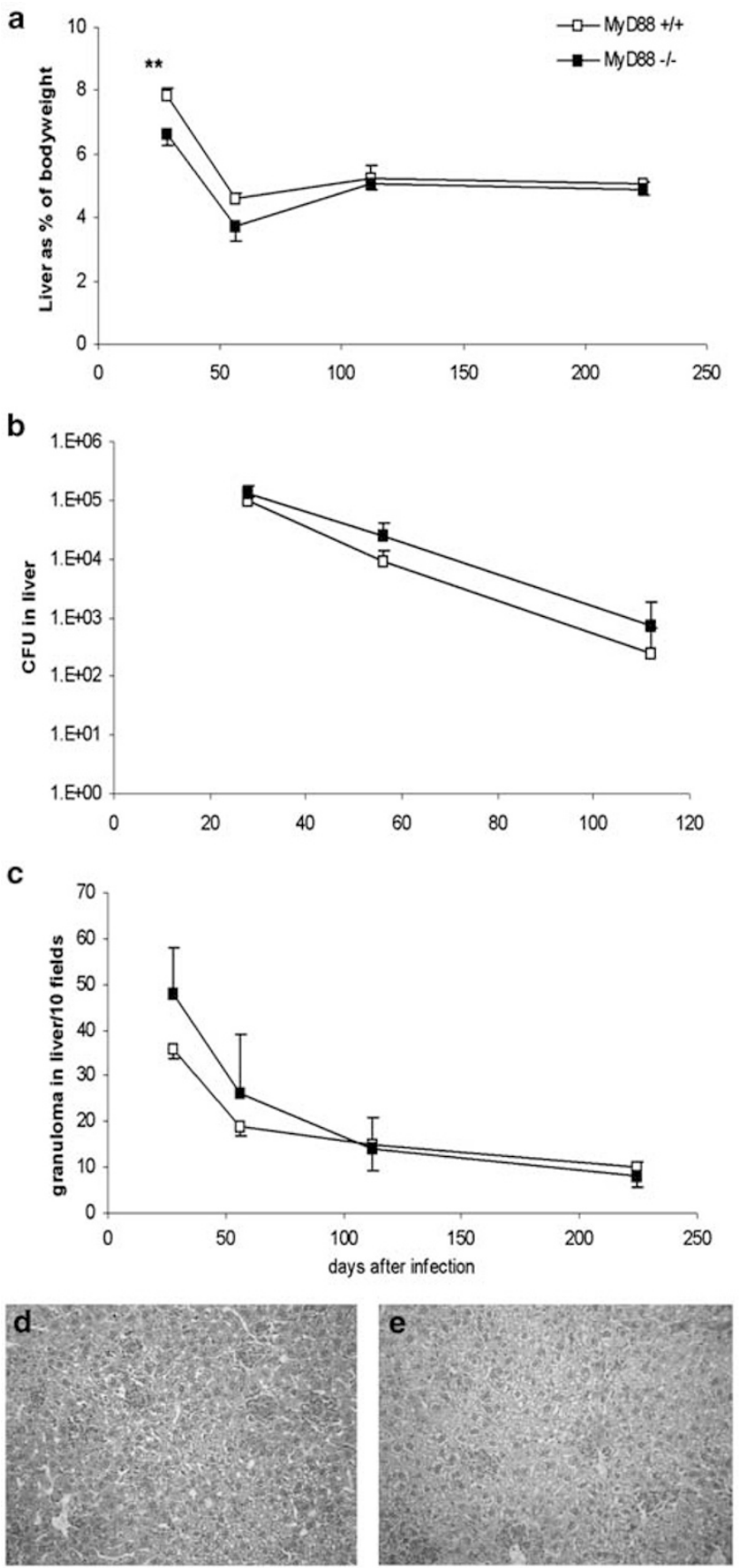

Figure 6 Controlled inflammatory response with hepatic granuloma formation and clearance of M. bovis BCG bacilli in MyD88deficient mice. MyD88-deficient (closed symbols) and control mice (open symbols) were infected with BCG $\left(2 \times 10^{6} \mathrm{CFU} /\right.$ mouse i.v.). (a) Liver relative weights expressed as \% of body weight (mean \pm s.d., $n=3$ mice). (b) Viable bacteria assessed by counting CFU from liver homogenates, expressed as mean CFU values per whole organ \pm s.d. $(n=3$ mice, $P>0.05)$. (c) Compilation of the hepatic granuloma counts over time (mean \pm s.d., $n=3$ mice, $P>0.05)$. (d, e) Haematoxylin-eosin staining of liver; representative sections were selected (magnification $\times 200$ ).

MyD88-deficient mice. At day 155 postinfection, where pulmonary pathology was clearly more prominent in MyD88-deficient mice, we found a slight, but not significant reduction of IFN $\gamma$ produc-
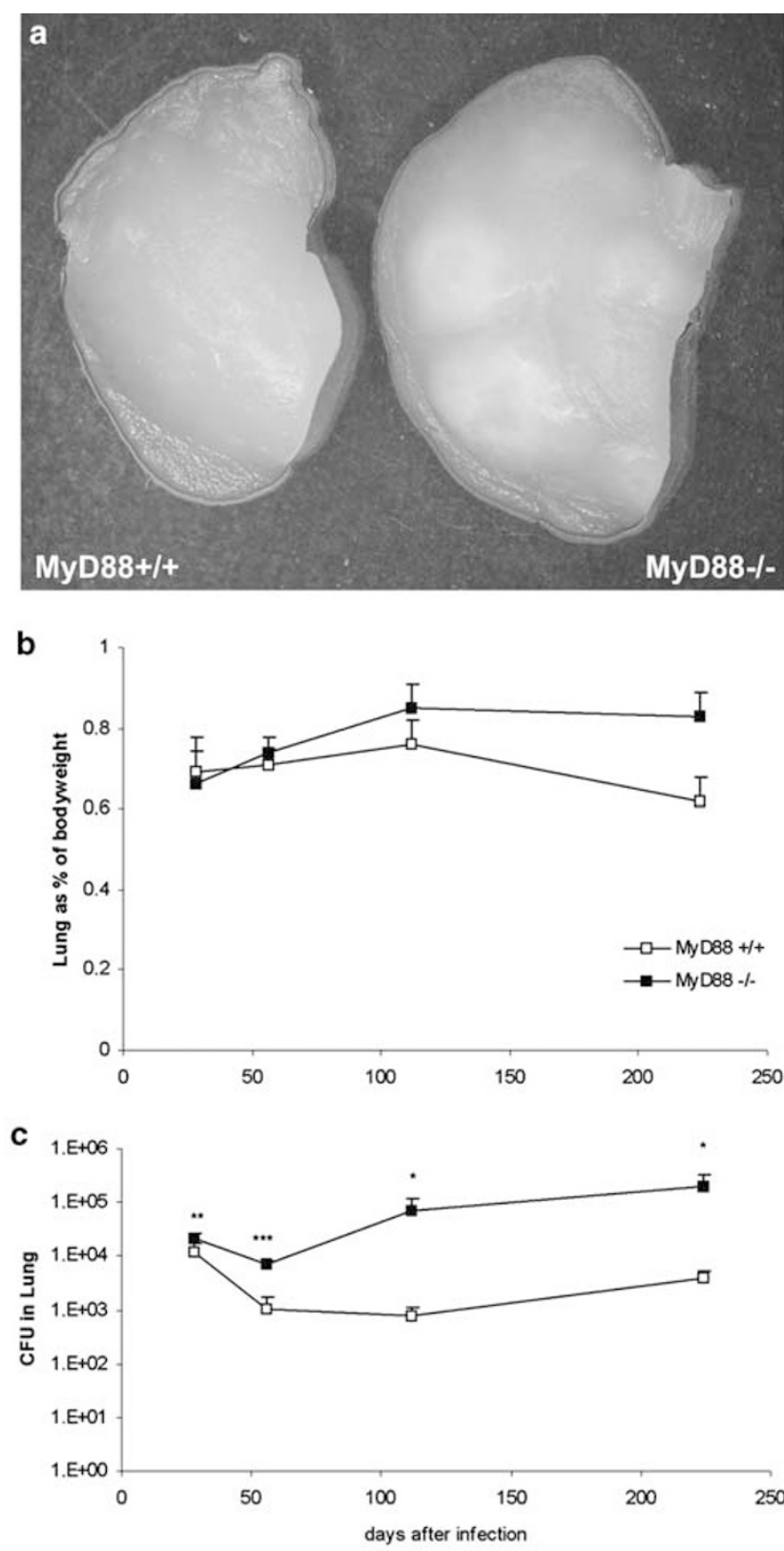

Figure 7 Macroscopic pulmonary nodules, increased lung weight and bacterial load in $M$. bovis BCG-infected MyD88-deficient mice. MyD88-deficient (closed symbols) and control mice (open symbols) were infected with BCG $\left(2 \times 10^{6} \mathrm{CFU} /\right.$ mouse i.v.), as in Figure 6. (a) Lung macroscopic nodules in MyD88-deficient mice (right) and in wild-type mice (left) are analysed on day 224 after infection. (b) Lung relative weights expressed as \% of body weight (mean + s.d., $n=3$ mice, $P=0.06$ at day 224). (c) Viable bacteria assessed by counting CFU from lung homogenates, expressed as mean values per whole organ \pm s.d. $\left(n=3\right.$ mice, ${ }^{*} P<0.05$, $\left.{ }^{*} P<0.01\right)$.

tion by MyD88-deficient lung infiltrating cells upon restimulation with soluble BCG antigens (Figure 10a). IL-10 production was significantly reduced in these cells stimulated with BCG antigens or HKLM (data not shown). The number of cells recovered from the lung homogenate was reduced by $53 \%$ in 
MyD88-deficient mice at 155 days, which may in part be due to the cellular organisation in nodules. We next characterised the immunoinflammatory cells recruited in the lung parenchyma and BAL fluid by flow cytometry. There was no significant difference in the proportion of macrophages, DCs, and neutrophils, CD4 + and CD8 + T cells in the lung of BCG-infected MyD88-deficient vs. control mice at 155 days (Figure 10b). Further, the activation of the pulmonary CD4 + and CD8 $+\mathrm{T}$ cells as assessed by the expression of CD25 and CD44 was not different in the two groups of mice, indicating that memory CD4 and CD8 T cells were present and a large proportion of the $\mathrm{T}$ cells were activated (Figure 10c). However, in the BAL, the differences were pronounced with significant reduction of the proportion of macrophages, DCs and CD8 + T cells in BCG-infected MyD88-deficient mice (Figure 10d). Extravasation to the alveolar space might be hampered due to the extensive inflammation and the organisation in nodules in the lungs of MyD88deficient mice. The expression of the activation markers CD44 and CD25 on CD8 + T cells, but not $\mathrm{CD} 4+\mathrm{T}$ cells, was significantly reduced in the BAL of MyD88-deficient mice (Figure 10e), suggesting that memory and/or activated $\mathrm{T}$ cells might be retained at the pulmonary site of infection.

Earlier pulmonary immune response was then examined at 4 weeks postinfection, when lung pathology is similar and bacterial load in the same order of magnitude in control versus deficient mice (1.2 vs $2.2 \times 10^{4} \mathrm{CFU}$, respectively). At day 28 postinfection, IFN $\gamma$ production by unseparated lung infiltrating cells upon restimulation with soluble BCG antigens was evident both MyD88-deficient and wild-type mice (with reduced levels in only one out of four MyD88-deficient mice; Figure 11a). The proportion of the different cell types, $\mathrm{T}$ cells, macrophages and granulocytes, was similar in both types of mice (Figure 11b), as was the expression of T-cell activation markers CD25 and CD44 (Figure 11c). Opposite to what was observed at day 155, the number of activated (CD25 +) T cells was low at day 28. CD $4+\mathrm{CD} 44+$ and CD8 $+\mathrm{CD} 44+$ memory $\mathrm{T}$ cells were already abundant 28 days postinfection. Unseparated lung infiltrating cells from MyD88deficient mice restimulated with BCG antigens or HKLM showed a clear defect in the production of nitric oxide or IL-10 as compared with wild-type cells (data not shown).

Pulmonary CD4 $+\mathrm{T}$ cells response was further examined. At 4 weeks postinfection IFN $\gamma$ production by purified CD4 + lung infiltrating cells upon restimulation with soluble BCG antigens was present, although partially reduced in MyD88-deficient mice (Figure 11d). At this time point, there were few cells extravasing into the bronchoalveolar space $\left(3-7 \times 10^{4}\right.$ cells $)$, as in naïve mice $\left(5-10 \times 10^{4}\right.$ cells $)$.

The data indicate that during the early and chronic phases of infection there is recruitment and activation of antigen-presenting cells and T cells in the lung of MyD88-deficient mice, but that there is an impairment of NO and IL-10 production, and a slight reduction in IFN $\gamma$ levels.

\section{Discussion}

We show here that the adaptor protein MyD88 involved in TLR/IL-1R signalling is required to control pulmonary infection by $M$. bovis BCG, resulting in chronic pneumonia, but is not necessary to clear the bacilli from the other organ sites. Reduced resistance to BCG infection was expected as the in vitro responses of MyD88-deficient macrophages and DCs to BCG antigens were strongly reduced and the internalisation of GFP-BCG impaired.

Particulate or soluble fractions of BCG could not activate MyD88-deficient macrophages, in agreement with their strong TLR2 agonist activity (DN, VQ, unpublished data), likely to be MyD88-dependent. MyD88-deficient macrophages showed a clear defect in $\mathrm{NF} \kappa \mathrm{B}$ translocation in response to live BCG infection, although they produce minute levels of cytokines and nitric oxide. MyD88-independent pathways which may be involved in BCG binding and recognition include the complement receptors CR3 (CD11b/CD18) and CR4 (CD11c/CD18), scavenger receptor, mannose receptor, DC-specific intracellular adhesion molecule-3 grabbing nonintegrin (reviewed in Heldwein and Fentorn ${ }^{4}$ and Kaufmann and Schaible). ${ }^{36}$ TLR4 may also signal through MyD88-independent pathways, as demonstrated for LPS stimulation. ${ }^{19}$ How the different receptors contribute to the proinflammatory response to BCG is still unclear and we show here that MyD88-deficient macrophages had an impaired internalisation of fluorescent GFP-expressing BCG (Table 1).

Mycobacteria contained in endosomes of macrophages have been shown to release soluble antigens, such as PIM, LM or LAM into the cytosol of the host cells, and these molecules may be taken up by neighbouring, noninfected cells. ${ }^{33}$ PIM and LM, plus other soluble antigens, are likely to further trigger TLR2-dependent proinflammatory responses. ${ }^{34,35}$ This proinflammatory stimulation by mycobacterial cell wall components is unlikely to occur in MyD88deficient cells. Conversely, LAM and LM have been shown to have anti-inflammatory properties, inhibiting endotoxin-stimulated production of IL-12 and TNF in DCs and macrophages, ${ }^{37}$ by a pathway independent of TLR2, TLR4, TLR6 and MyD88. ${ }^{35}$ Thus, in MyD88-deficient mice, the anti-inflammatory effects of LM and LAM may be present, but not the proinflammatory effects of LM, PIMs and other mycobacterial antigens.

MyD88-deficient DCs responded to infection with live BCG, or to stimulation by an extended freezedried BCG preparation, by secreting TNF and IL$12 \mathrm{p} 40$ at levels at least similar to those observed 

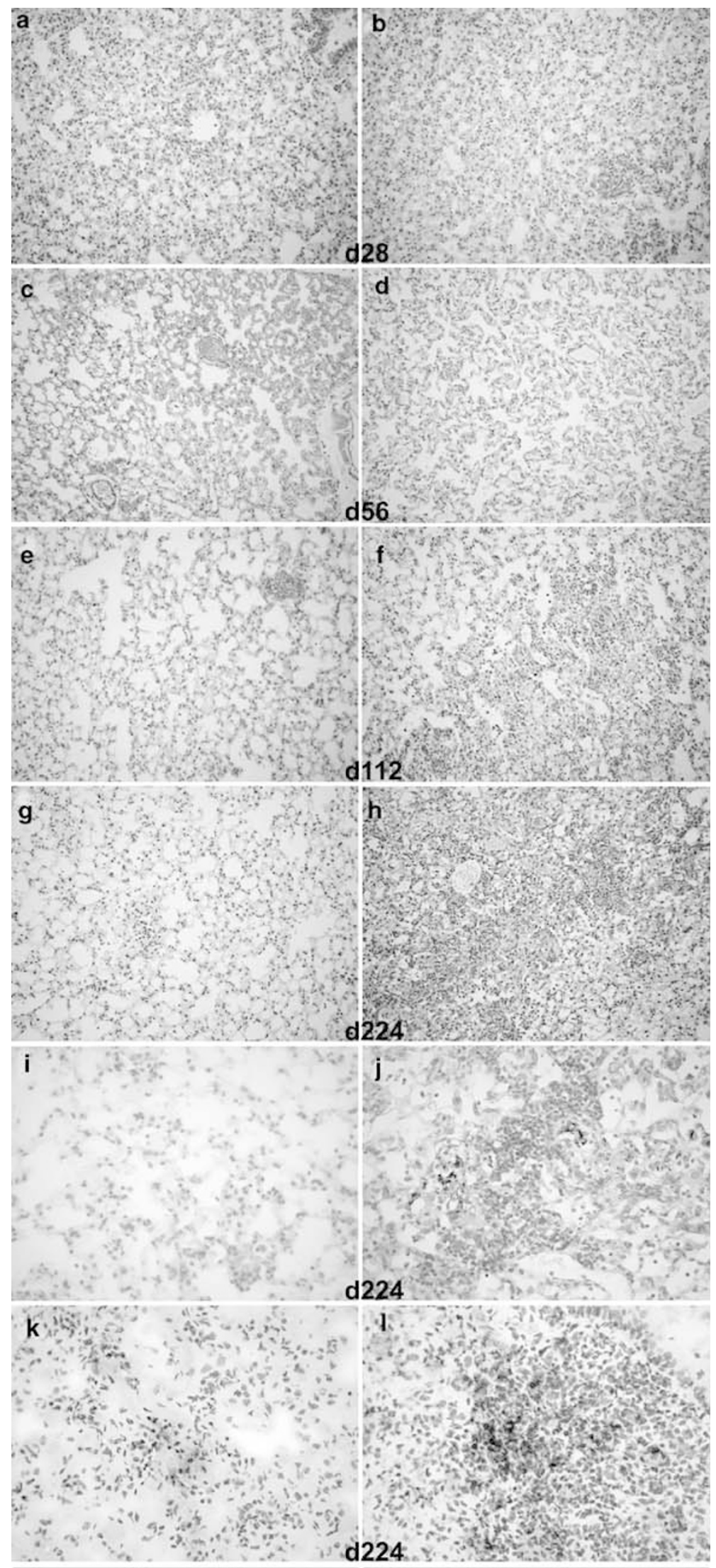

MyD88+/+

MyD88-/- 

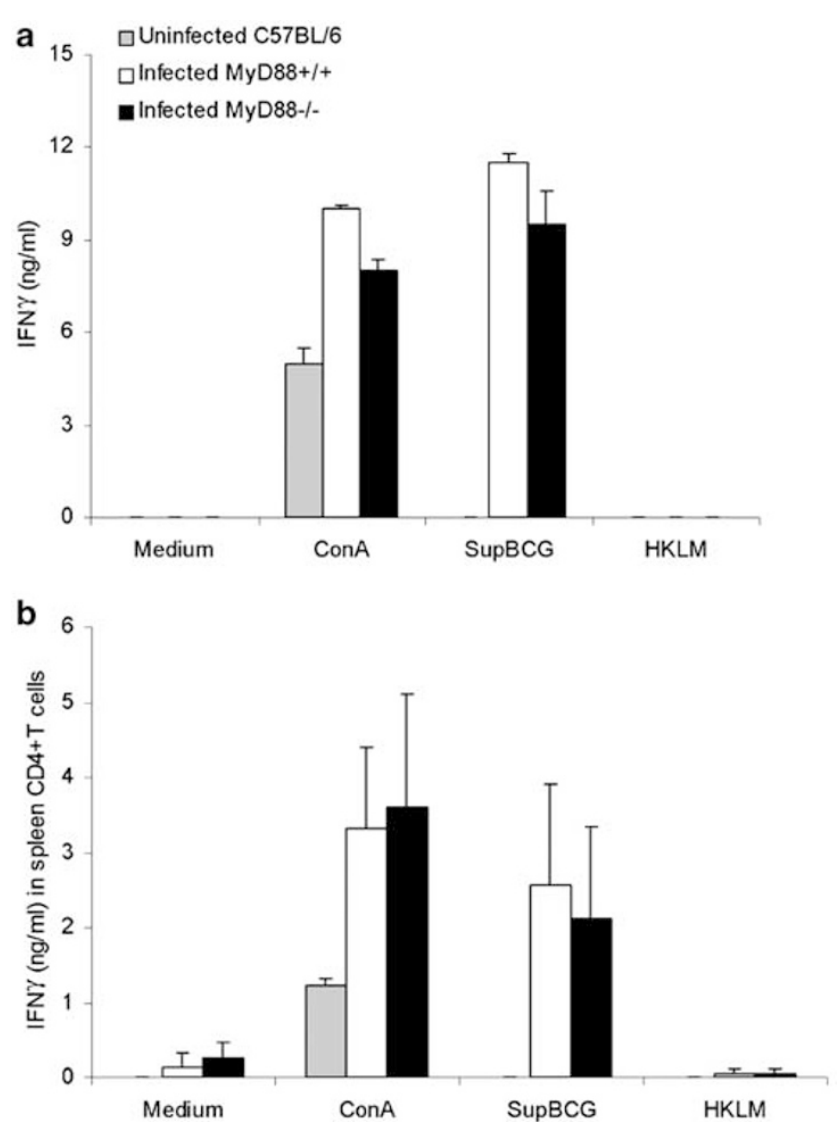

Figure 9 Adaptive immune response to $M$. bovis BCG in MyD88deficient mice. (a) Splenocytes isolated from $M$. bovis BCGinfected control and MyD88-deficient 4 weeks after inoculation $\left(2 \times 10^{6} \mathrm{CFU} / \mathrm{mouse}\right.$ i.v. $)$, or from uninfected control mice, were restimulated in vitro in the presence of soluble BCG antigens (Sup BCG, $30 \mu \mathrm{g} / \mathrm{ml}$ ) or an unrelated antigen, HKLM (100 bacteria/cell). IFN $\gamma$ production was quantified in the supernatants after $48 \mathrm{~h}$ of incubation. Results are from $n=3$ mice per genotype and are from one representative experiment out of three independent experiments. (b) Purified CD4 + splenocytes were stimulated as in (a) and IFN $\gamma$ production quantified in the supernatants after $48 \mathrm{~h}$ of incubation. Results are mean + s.d. from $n=4$ mice per genotype.

with LPS. Thus, DC may be activated during BCG infection, even in the absence of MyD88. The maturation of MyD88-deficient DC was confirmed in terms of CD40 and CD86 costimulatory molecule expression after incubation with BCG. Maturation of DCs by heat-killed $M$. tuberculosis was reported to be MyD88-dependent, ${ }^{38}$ but we show here that the response to heat-killed and live mycobacteria are likely to be different. Here, both macrophages and DCs infected with BCG, or stimulated with LPS, were able to express costimulatory molecules in the absence of functional MyD88 pathway, in line with the reported MyD88-independent maturation of endotoxin-stimulated DC. ${ }^{18}$ Reduced MHC class II expression after stimulation with mycobacterial $19 \mathrm{kDa}$ protein and reduced Ag processing after $M$. $t b$ infection was shown by Noss et $a l,{ }^{39}$ but these reductions were not seen in TLR2-deficient cells. Along these lines, we show here that in the absence of MyD88 signalling, MHC class II expression is rather slightly increased. Together with the efficient expression of costimulatory molecules, it is therefore expected that MyD88-null macrophages and DCs can efficiently trigger $\mathrm{T}$ cells. Indeed, T-cell priming to BCG antigens in vivo seemed to occur since a strong IFN $\gamma$ response was observed upon $e x$ vivo CD4 + T cells restimulation with mycobacterial antigens. These data are in line with the efficient functional maturation of endotoxin-treated MyD88deficient DC reported by Kaisho et al, ${ }^{18}$ but contrast with the defective MyD88-deficient DC maturation observed in response to heat-killed $M$. tuberculosis. $^{38}$ Feng et $a l^{26}$ showed an impairement of early IFN $\gamma$ T-cell responses (up to 3 weeks postinfection). We show here that MyD88-deficient mice are able to mount IFN $\gamma$ T-cell responses at later time points after BCG infection.

The low virulence model established with attenuated $M$. bovis BCG allows us to separate two functions of the innate cells upon mycobacteria contact, that is, the secretion of proinflammatory cytokines and mediators like nitric oxide by phagocytes, on the one hand, and the expression of costimulation and MHC class II molecules by the antigen-presenting cells, which led to the recruitment and activation of an effective adaptive response, on the other hand. In a more virulent model, such as aerogenic infection by $M$. tuberculosis, absence of MyD88 leads to a rapid morbidity and mortality (data not shown). In the attenuated BCG infection model, however, the initially reduced proinflammatory cytokines response and nitrite production, by MyD88-deficient phagocytes were not fatal. MyD88-deficient mice were able to control the infection and to survive the extended observation period of 8 months with no obvious clinical signs. Thus, the early, proinflammatory component of the innate response is not essential for early bacterial control following BCG infection. The adaptive response triggered by activated antigenpresenting cells seems thereafter sufficient to control systemic BCG infection. Indeed, efficient CD4+ T-cell priming was found in MyD88-deficient mice upon ex vivo restimulation with mycobacterial antigens.

Figure 8 Increased inflammation, absence of granuloma and abundant mycobacteria in lungs of MyD88-deficient mice. MyD88-deficient $(\mathbf{b}, \mathbf{d}, \mathbf{f}, \mathbf{h}, \mathbf{j}, \mathbf{l})$ and control $(\mathbf{a}, \mathbf{c}, \mathbf{e}, \mathbf{g}, \mathbf{i}, \mathbf{k})$ mice were infected with BCG $\left(2 \times 10^{6} \mathrm{CFU} / \mathrm{mouse}\right.$ i.v. $)$, as in Figure 6 (a-h) Haematoxylin-eosin staining of lung sections were examined at day $28(\mathbf{a}, \mathbf{b}), 56(\mathbf{c}, \mathbf{d}), 112(\mathbf{e}, \mathbf{f})$ and $224(\mathbf{g}, \mathbf{h})$ postinfection and representative sections were selected (magnification $\times 200$ ). (i, j) Pulmonary M. bovis BCG bacilli were visualised by Ziehl-Neelsen staining and representative sections were selected (magnification $\times 400)$. $(\mathbf{k}, \mathbf{l})$ iNOS staining determined by immunohistochemistry on day 224 postinfection (magnification $\times 400)$. 

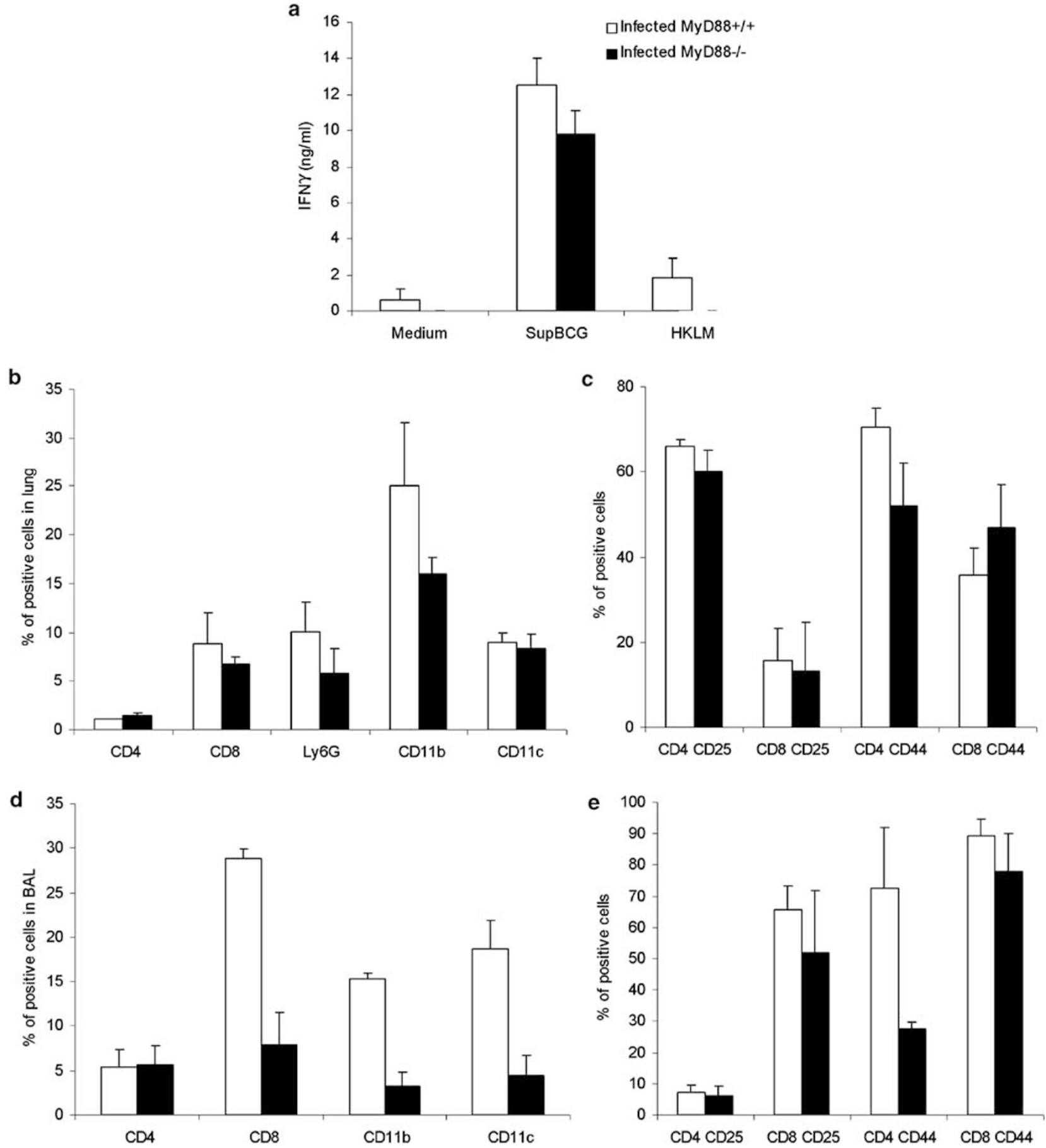

Figure 10 Reactivation of lung infiltrating cells 5 months after BCG infection in the absence of MyD88. (a) Lung cells isolated from M. bovis BCG-infected control and MyD88-deficient 5 months after inoculation $\left(2 \times 10^{6} \mathrm{CFU} / \mathrm{mouse}\right.$ i.v. $)$, were restimulated in vitro in the presence of soluble BCG antigens (Sup BCG, $30 \mu \mathrm{g} / \mathrm{ml}$ ) or an unrelated antigen, HKLM (100 bacteria/cell). IFN $\gamma$ production was quantified in the supernatants after $48 \mathrm{~h}$ of incubation. Results are mean + s.d. from $n=3$ mice per genotype. (b-e) Cells obtained from lung homogenates (b, c) and BAL (d, e) were stained for expression of CD11b, CD11c, Ly-6G, CD4, CD8, CD44 and CD25 by flow cytometry. Results are expressed as mean + s.d. of the percentage of positively stained cells and are from $n=3$ mice per genotype.

Alternatively, it cannot be excluded that the reduced MyD88 independent, proinflammatory component present in MyD88-deficient mice was sufficient to sustain early bacterial control. The relative resistance of MyD88-deficient mice con- trasts with the rapid death observed in the absence of TNF after systemic BCG infection, usually within 2-3 months. ${ }^{40,41}$ However, low levels of local TNF suffice to prevent mortality in TNF-deficient mice infected with TNF-expressing recombinant BCG. ${ }^{42}$ 
Therefore, in MyD88-deficient mice activated T cells or alternative sources might produce enough TNF to control BCG infection.

While systemic infection was controlled, pulmonary infection and pathology became prominent in
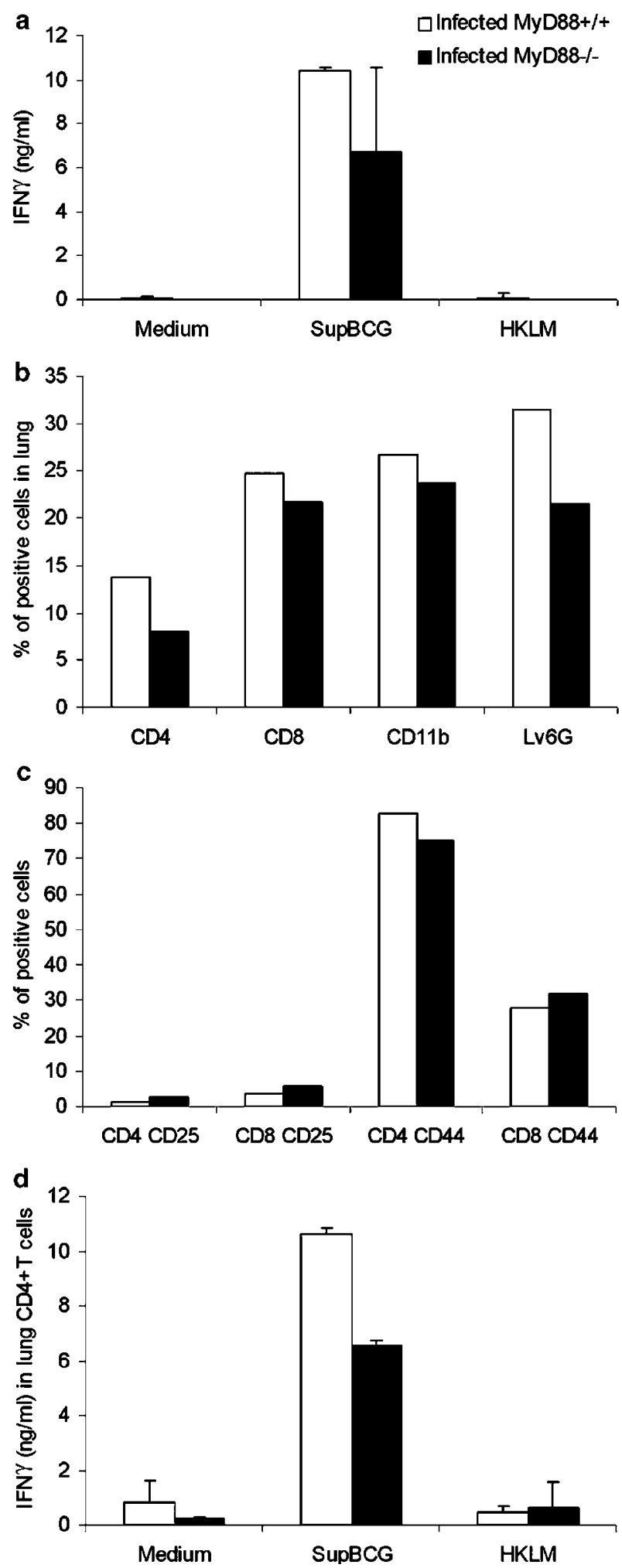

the chronic phase in MyD88-deficient mice with reduced bacterial clearance. The alveolar space may represent a special niche for mycobacterial survival with high oxygen partial pressure (reviewed in McKinney et $a l^{43}$ ). We show that MyD88-deficient macrophages have a reduced capacity to phagocytose mycobacteria (Table 1). A TLR-MyD88-dependent induction of a phagocytic gene programme has been shown for E $\mathrm{Coli}^{44}$ with MyD88-, TLR2and TLR9-dependent phagocytosis of bacteria. Therefore, the defect of innate immunity is complex with MyD88-deficient macrophages having a reduced capacity to ingest mycobacteria, reduced proinflammatory cytokines response and reduced IFN $\gamma$ responsiveness. ${ }^{45}$ IFN $\gamma$ production by $\mathrm{CD} 4+\mathrm{T}$ cells was not significantly reduced during disease progression in MyD88-deficient mice, although a trend towards lower IFN $\gamma$ production was noted in the lungs. A strong defect in NO production by lung infiltrating cells upon ex vivo restimulation was noted in MyD88-deficient mice, which may contribute to the defective mycobacterial control. IL-10 production by these cells was impaired, and this may play a role in exacerbating the lung inflammatory process in BCG-infected MyD88-deficient mice. Therefore, despite the T-cell IFN $\gamma$ response, the defect of innate immunity could not be overcome. In the chronic phase of the infection, there was relatively less activated $T$ cells in the alveolar space in MyD88-deficient mice, concomitant with reduced extravasation of antigen-presenting cells. This may be linked to the presence of large inflammatory nodules in the lungs of these mice. MyD88 signalling might be important for the production of critical chemokines allowing the cell migration into the alveolar space. Therefore, MyD88 appears to be critical to activate antigen-presenting cells which may contribute to the progression of the lung pathology.

It cannot be excluded at this point that MyD88 pathway is specifically important in lung endothelial/epithelial cells. It has been recognised recently that TLR4 on lung endothelial cells play a pivotal role in the massive neutrophil accumulation follow-

Figure 11 Reactivation of lung infiltrating $\mathrm{T}$ cells 28 days after BCG infection in the absence of MyD88. (a) Lung cells isolated from $M$. bovis BCG-infected control and MyD88-deficient 28 days after inoculation $\left(2 \times 10^{6} \mathrm{CFU} /\right.$ mouse i.v. $)$, were restimulated in vitro in the presence of soluble BCG antigens (Sup BCG, $30 \mu \mathrm{g} / \mathrm{ml}$ ) or an unrelated antigen, HKLM (100 bacteria/cell). IFN $\gamma$ production was quantified in the supernatants after $48 \mathrm{~h}$ of incubation. Results are mean + s.d. from $n=4$ mice per genotype. (b and c) Cells obtained from lung homogenates were stained for expression of CD11b, Ly-6G, CD4, CD8, CD25 and CD44 by flow cytometry. Results are expressed as percentage of positively stained cells and are from pooled lung cell preparations from $n=4$ mice per genotype. (d) Purified CD4 + lung infiltrating cells were stimulated as in (a) and IFN $\gamma$ production quantified in the supernatants after $48 \mathrm{~h}$ of incubation. Results are mean + s.d. from duplicates of pooled CD4 + lung cell preparations from $n=4$ mice per genotype. 
ing i.p. endotoxin administration. ${ }^{46}$ Mycobacterial infection in bone marrow chimaera should be instrumental to differentiate the specific consequence of MyD88 deficiency in haematopoietic cells vs epithelial/endothelial cells of the lung environment.

In summary, MyD88 is dispensable to mount an adaptive immune response able to control systemic BCG infection, but is critical to control mycobacterial replication in the lung resulting in chronic, progressive pulmonary BCG infection.

\section{Acknowledgements}

The project was supported by CNRS and a doctoral fellowship from the 'Conseil Regional du Centre', France (DMN). This work was also supported by a Franco-South-African Research Cooperation Program grant. D Nicolle received a student bursary of Conseil Regional du Centre, France. We are grateful to Dr Marie-Noelle Soler for skillful assistance in preparing the manuscript.

\section{References}

1 Takeda K, Kaisho T, Akira S. Toll-like receptors. Annu Rev Immunol 2003;21:335-376.

2 Means TK, Wang S, Lien E, et al. Human Toll-like receptors mediate cellular activation by Mycobacterium tuberculosis. J Immunol 1999;163:3920-3927.

3 Means TK, Jones BW, Schromm AB, et al. Differential effects of a Toll-like receptor antagonist on Mycobacterium tuberculosis-induced macrophage responses. J Immunol 2001;166:4074-4082.

4 Heldwein KA, Fenton MJ. The role of Toll-like receptors in immunity against mycobacterial infection. Microbes Infect 2002;4:937-944.

5 Tsuji S, Matsumoto M, Takeuchi O, et al. Maturation of human dendritic cells by cell wall skeleton of Mycobacterium bovis bacillus Calmette-Guerin: involvement of Toll-like receptors. Infect Immun 2000; 68:6883-6890.

6 Noss EH, Pai RK, Sellati TJ, et al. Toll-like receptor 2dependent inhibition of macrophage class II MHC expression and antigen processing by 19-kDa lipoprotein of Mycobacterium tuberculosis. J Immunol 2001; 167:910-918.

7 Thoma-Uszynski S, Stenger S, Takeuchi O, et al. Induction of direct antimicrobial activity through mammalian Toll-like receptors. Science 2001;291: 1544-1547.

8 Fremond CMC, Nicolle DMM, Torres DS, et al. Control of Mycobacterium bovis BCG infection with increased inflammation in TLR4-deficient mice. Microbes Infect 2003;5:1070.

9 Drennan MB, Nicolle D, Quesniaux VJ, et al. Toll-Like receptor 2-deficient mice succumb to Mycobacterium tuberculosis infection. Am J Pathol 2004;164:49-57.

10 Abel B, Thieblemont N, Quesniaux VJ, et al. Toll-like receptor 4 expression is required to control chronic Mycobacterium tuberculosis infection in mice. J Immunol 2002;169:3155-3162.
11 Reiling N, Holscher C, Fehrenbach A, et al. Cutting edge: Toll-like receptor (TLR)2- and TLR4-mediated pathogen recognition in resistance to airborne infection with Mycobacterium tuberculosis. J Immunol 2002;169:3480-3484.

12 Branger J, Leemans JC, Florquin S, et al. Toll-like receptor 4 plays a protective role in pulmonary tuberculosis in mice. Int Immunol 2004;16:509-516.

13 Yamamoto M, Sato S, Hemmi H, et al. Role of adaptor TRIF in the MyD88-independent Toll-like receptor signaling pathway. Science 2003;301:640-643.

14 Oshiumi H, Matsumoto M, Funami K, et al. TICAM-1, an adaptor molecule that participates in Toll-like receptor 3-mediated interferon-beta induction. Nat Immunol 2003;4:161-167.

15 O’Neill LA, Fitzgerald KA, Bowie AG. The Toll-IL-1 receptor adaptor family grows to five members. Trends Immunol 2003;24:286-289.

16 Medzhitov R, Preston-Hurlburt P, Kopp E, et al. MyD88 is an adaptor protein in the hToll/IL-1 receptor family signaling pathways. Mol Cell 1998;2:253-258.

17 Takeuchi O, Takeda K, Hoshino K, et al. Cellular responses to bacterial cell wall components are mediated through MyD88-dependent signaling cascades. Int Immunol 2000;12:113-117.

18 Kaisho T, Takeuchi O, Kawai T, et al. Endotoxininduced maturation of MyD88-deficient dendritic cells. J Immunol 2001;166:5688-5694.

19 Kawai T, Takeuchi O, Fujita T, et al. Lipopolysaccharide stimulates the MyD88-independent pathway and results in activation of IFN-regulatory factor 3 and the expression of a subset of lipopolysaccharide-inducible genes. J Immunol 2001;167:5887-5894.

20 Kawai T, Adachi O, Ogawa T. Unresponsiveness of MyD88-deficient mice to endotoxin. Immunity 1999; 11:115-122.

21 Adachi O, Kawai T, Takeda K, et al. Targeted disruption of the MyD88 gene results in loss of IL-1- and IL18-mediated function. Immunity 1998;9:143-150.

22 Weighardt H, Kaiser-Moore S, Vabulas RM, et al. Cutting edge: myeloid differentiation factor 88 deficiency improves resistance against sepsis caused by polymicrobial infection. J Immunol 2002;169: 2823-2827.

23 Takeuchi O, Hoshino K, Akira S. Cutting edge: TLR2deficient and MyD88-deficient mice are highly susceptible to Staphylococcus aureus infection. J Immunol 2000;165:5392-5396.

24 Scanga CA, Aliberti J, Jankovic D, et al. Cutting edge: MyD88 is required for resistance to Toxoplasma gondii infection and regulates parasite-induced IL-12 production by dendritic cells. J Immunol 2002;168: 5997-6001.

25 Way SS, Kollmann TR, Hajjar AM, et al. Protective cell-mediated immunity to Listeria monocytogenes in the absence of myeloid differentiation factor 88 . J Immunol 2003;171:533-537.

26 Feng CG, Scanga CA, Collazo-Custodio CM, et al. Mice lacking myeloid differentiation factor 88 display profound defects in host resistance and immune responses to Mycobacterium avium infection not exhibited by Toll-like receptor 2 (TLR2)- and TLR4deficient animals. J Immunol 2003;171:4758-4764.

27 Muller M, Eugster HP, Le Hir M, et al. Correction or transfer of immunodeficiency due to TNF-LT alpha deletion by bone marrow transplantation. Mol Med 1996;2:247-255. 
28 Lutz MB, Kukutsch N, Ogilvie AL, et al. An advanced culture method for generating large quantities of highly pure dendritic cells from mouse bone marrow. J Immunol Methods 1999;223:77-92.

29 Hubeau C, Singer M, Lagranderie M, et al. Extended freeze-dried Mycobacterium bovis bacillus CalmetteGuerin induces the release of interleukin-12 but not tumour necrosis factor-alpha by alveolar macrophages, both in vitro and in vivo. Clin Exp Allergy 2003; 33:386-393.

30 Green LC, Wagner DA, Glogowski J, et al. Analysis of nitrate, nitrite, and [15N]nitrate in biological fluids. Anal Biochem 1982;126:131-138.

31 Lyadova IV, Eruslanov EB, Khaidukov SV, et al. Comparative analysis of $\mathrm{T}$ lymphocytes recovered from the lungs of mice genetically susceptible, resistant, and hyperresistant to Mycobacterium tuberculosis-triggered disease. J Immunol 2000;165:5921-5931.

32 Botha T, Ryffel B. Reactivation of latent tuberculosis infection in TNF-deficient mice. J Immunol 2003; 171:3110-3118.

33 Beatty WL, Rhoades ER, Ullrich HJ, et al. Trafficking and release of mycobacterial lipids from infected macrophages. Traffic 2000;1:235-247.

34 Gilleron M, Quesniaux VF, Puzo G. Acylation state of the phosphatidylinositol hexamannosides from Mycobacterium bovis bacillus Calmette-Guerin and Mycobacterium tuberculosis $\mathrm{H} 37 \mathrm{Rv}$ and its implication in Toll-like receptor response. J Biol Chem 2003;278: 29880-29889.

35 Quesniaux VJ, Nicolle DM, Torres D, et al. Toll-like receptor 2 (TLR2)-dependent-positive and TLR2-independent-negative regulation of proinflammatory cytokines by mycobacterial lipomannans. J Immunol 2004; 172:4425-4434.

36 Kaufmann SH, Schaible UE. A dangerous liaison between two major killers: Mycobacterium tuberculosis and HIV target dendritic cells through DC-SIGN. J Exp Med 2003;197:1-5.
37 Nigou J, Zelle-Rieser C, Gilleron M, et al. Mannosylated lipoarabinomannans inhibit IL-12 production by human dendritic cells: evidence for a negative signal delivered through the mannose receptor. J Immunol 2001;166:7477-7485.

38 Schnare M, Barton GM, Holt AC, et al. Toll-like receptors control activation of adaptive immune responses. Nat Immunol 2001;2:947-950.

39 Noss EH, Harding CV, Boom WH. Mycobacterium tuberculosis inhibits MHC class II antigen processing in murine bone marrow macrophages. Cell Immunol 2000;201:63-74.

40 Jacobs M, Brown N, Allie N, et al. Fatal Mycobacterium bovis BCG infection in TNF-LT-alpha-deficient mice. Clin Immunol 2000;94:192-199.

41 Jacobs M, Marino MW, Brown N, et al. Correction of defective host response to Mycobacterium bovis BCG infection in TNF-deficient mice by bone marrow transplantation. Lab Invest 2000;80: 901-914.

42 Bekker LG, Moreira AL, Bergtold A, et al. Immunopathologic effects of tumor necrosis factor alpha in murine mycobacterial infection are dose dependent. Infect Immun 2000;68:6954-6961.

43 McKinney J, Jacobs WR, Bloom BR. Persisting problems in tuberculosis. In: Krause RM (ed). Emerging Infections. Academic Press: New York, NY, 1998, pp 51-146.

44 Doyle SE, O’Connell RM, Miranda GA, et al. Toll-like receptors induce a phagocytic gene program through p38. J Exp Med 2004;199:81-90.

45 Shi S, Nathan C, Schnappinger D, et al. MyD88 Primes macrophages for full-scale activation by interferon- $\gamma$ yet mediates few responses to Mycobacterium tuberculosis. J Exp Med 2003;198:987-997.

46 Andonegui G, Bonder CS, Green F, et al. Endotheliumderived Toll-like receptor-4 is the key molecule in LPS-induced neutrophil sequestration into lungs. J Clin Invest 2003;111:1011-1020. 